Received: 9 March 2018

Accepted: 16 May 2018

Published online: 29 May 2018

\section{Compromised microvascular oxygen delivery increases brain tissue vulnerability with age}

\author{
Mohammad Moeini ${ }^{1,2,3}$, Xuecong Lu ${ }^{1,2}$, Pramod K. Avti ${ }^{1,2,7}$, Rafat Damseh ${ }^{1}$, Samuel Bélanger ${ }^{1,2}$, \\ Frédéric Picard ${ }^{4}$, David Boas ${ }^{5,6}$, Ashok Kakkar ${ }^{3}$ \& Frédéric Lesage ${ }^{1,2}$
}

Despite the possible role of impaired cerebral tissue oxygenation in age-related cognition decline, much is still unknown about the changes in brain tissue $\mathrm{pO}_{2}$ with age. Using a detailed investigation of the age-related changes in cerebral tissue oxygenation in the barrel cortex of healthy, awake aged mice, we demonstrate decreased arteriolar and tissue $\mathrm{pO}_{2}$ with age. These changes are exacerbated after middleage. We further uncovered evidence of the presence of hypoxic micro-pockets in the cortex of awake old mice. Our data suggests that from young to middle-age, a well-regulated capillary oxygen supply maintains the oxygen availability in cerebral tissue, despite decreased tissue $\mathrm{pO}_{2}$ next to arterioles. After middle-age, due to decreased hematocrit, reduced capillary density and higher capillary transit time heterogeneity, the capillary network fails to compensate for larger decreases in arterial $\mathrm{pO}_{2}$. The substantial decrease in brain tissue $\mathrm{pO}_{2}$, and the presence of hypoxic micro-pockets after middle-age are of significant importance, as these factors may be related to cognitive decline in elderly people.

It has been established that cognitive function declines even in healthy aging ${ }^{1-4}$. While the exact mechanisms are not known, declined cerebrovascular function has been the subject of intense investigation due to its crucial role in oxygen supply to the neuronal units ${ }^{5}$. Clinical findings show a correlation between cognitive impairment and vascular disorders ${ }^{6-8}$ as well as between cognitive impairment and cerebral blood flow $(\mathrm{CBF})^{3,9}$. These correlations suggest that gradual changes in the brain microvasculature and oxygen delivery which occur with aging may significantly contribute to cognition decline.

Cellular studies suggest that restricted oxygen supply can contribute to neuronal death and increased incidence of cognitive impairment by promoting reactive oxygen species (ROS) formation and calcium dyshomeostasis $^{10,11}$. Strikingly, it has been shown that hypoxia, even in vitro, promotes the formation of amyloid $\beta$ peptide, which is believed to be the primary neurotoxic element of Alzheimer's disease $(A D)^{10,11}$. There are several lines of evidence supporting the possible role of disrupted cerebral oxygenation in cognition decline. Clinical studies suggest that conditions which lead to restricted oxygen delivery to the brain promote the onset of cognitive disorders. In the extreme case of a stroke, the likelihood of developing dementia is several-fold higher in subjects that survive the event ${ }^{10,11}$. Oxygen supply to the brain is also globally decreased during high altitude excursions ${ }^{12}$ which are associated with cognitive defects in both human ${ }^{13-15}$ and experimental animals ${ }^{16}$. Furthermore, it has been shown in rats that intermittent hypoxia leads to increased incidence of neuronal death in the cortex ${ }^{17}$.

Despite its critical importance, to our knowledge, there is no data available in the literature regarding brain tissue $\mathrm{pO}_{2}$ (oxygen partial pressure) changes with age. Previous aging studies investigating brain oxygenation were limited to near-infrared spectroscopy (NIRS) and functional magnetic resonance imaging (fMRI) measurements of attenuated oxygenated and total hemoglobin concentration response to hypercapnic challenges ${ }^{18}$ or neuronal activation ${ }^{19-23}$. Translation of these findings to tissue $\mathrm{pO}_{2}$ is not straightforward because cerebral tissue $\mathrm{pO}_{2}$ is affected by several other factors, including CBF, geometry and morphology of the vascular network, capillary

${ }^{1}$ Biomedical Engineering Institute, École Polytechnique de Montréal, Montréal, OC, Canada. ${ }^{2}$ Research Center of Montreal Heart Institute, Montréal, OC, Canada. ${ }^{3}$ Department of Chemistry, McGill University, Montréal, OC, Canada. ${ }^{4}$ Centre de Recherche de I'Institut Universitaire de Cardiologie et Pneumologie de Québec (IUCPQ), Québec, QC, Canada. ${ }^{5}$ Athinoula A. Martinos Center for Biomedical Imaging, Massachusetts General Hospital, Harvard Medical School, Charlestown, MA, USA. ${ }^{6}$ Biomedical Engineering Department, College of Engineering, Boston University, Boston, MA, USA. ${ }^{7}$ Present address: Department of Biophysics, Postgraduate Institute of Medical Education and Research, Chandigarh, India. Correspondence and requests for materials should be addressed to F.L. (email: frederic.lesage@polymtl.ca) 
a

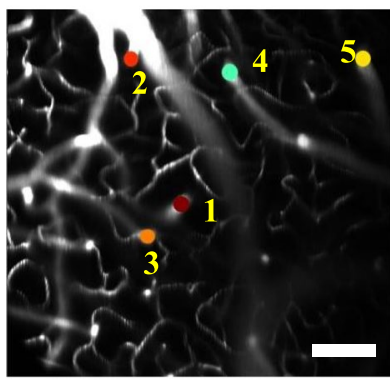

$20 \mu \mathrm{m}$ b

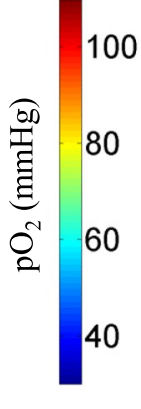

d

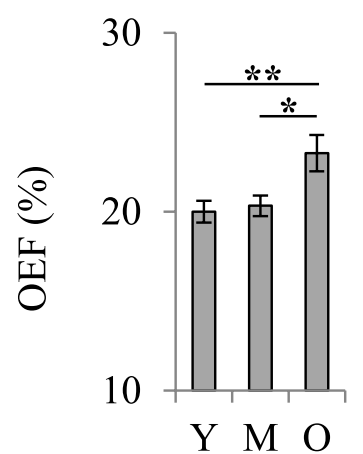

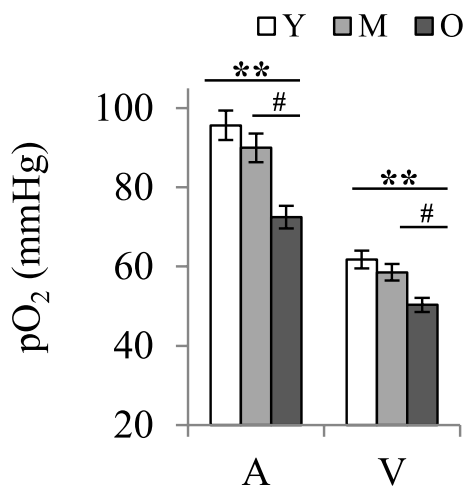

e

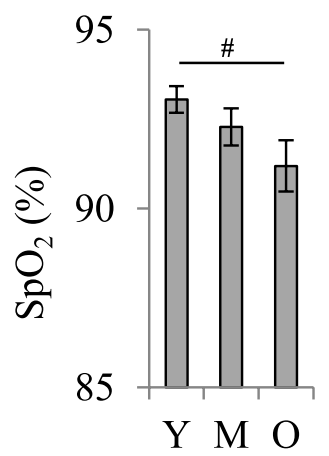

C

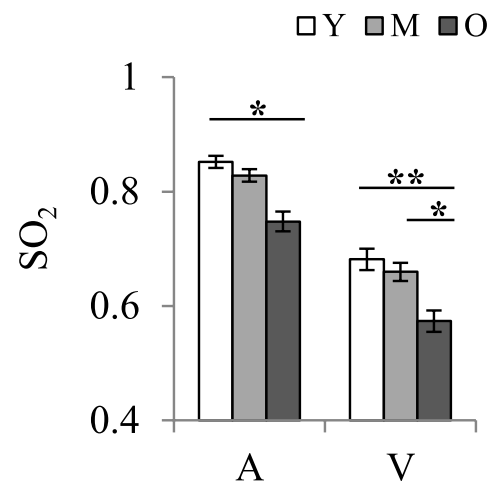

f

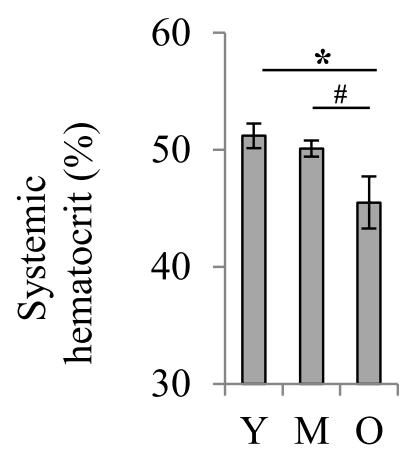

Figure 1. Decreased cerebral vascular oxygenation with age. (a) Examples of vascular $\mathrm{pO}_{2}$ imaging in diving arterioles (1-2) and ascending venules (3-5) at the depth of $\sim 20 \mu \mathrm{m}$ in a young mouse. The scale bar is $100 \mu \mathrm{m}$. $(\mathbf{b}, \mathbf{c})$ Changes in mean arteriolar $(\mathrm{A})$ and venular $(\mathrm{V}) \mathrm{pO}_{2}$ and $\mathrm{SO}_{2}$ with age. Mean $\mathrm{pO}_{2}$ and $\mathrm{SO}_{2}$ for each vessel were obtained by averaging the values over the first $150 \mu \mathrm{m}$ of depth. $\mathrm{pO}_{2}$ values were converted to $\mathrm{SO}_{2}$ using the Hill's equation (for arterioles: $\mathrm{Y}, \mathrm{n}=21 ; \mathrm{M}, \mathrm{n}=21 ; \mathrm{O}, \mathrm{n}=26$ vessels; for venules: $\mathrm{Y}, \mathrm{n}=23, \mathrm{M}, \mathrm{n}=25, \mathrm{O}$, $\mathrm{n}=31$ vessels; data from 8 young, 8 middle-aged, and 8 old mice). (d) Oxygen extraction fraction (OEF) versus age, obtained from $\mathrm{SO}_{2}$ values in (c). Error bars were obtained from $\mathrm{SO}_{2}$ standard deviations using the theory of error propagation. (e) Arterial oxygen saturation $\left(\mathrm{SpO}_{2}\right)$ measured by pulse oximetry on the tail $(\mathrm{Y}, \mathrm{n}=15$, $\mathrm{M}, \mathrm{n}=14, \mathrm{O}, \mathrm{n}=14$ mice). (f) Systemic hematocrit measured on a separate batch of mice (age-matched) by centrifugation of blood samples ( $Y, n=10, M, n=9, O, n=8$ mice). Y: young, M: middle-aged, O: old. Bar plots represent mean \pm s.e.m. Statistical significance was calculated using ANOVA followed by Tukey HSD post hoc test. $* * \mathrm{p}<0.01 * \mathrm{p}<0.05,{ }^{*} \mathrm{p}$-value approaches significance $(\mathrm{p}<0.1)$.

density, and the cerebral metabolic rate of oxygen consumption $\left(\mathrm{CMRO}_{2}\right)$; all of which are potentially modulated by age. Furthermore, the brain tissue $\mathrm{pO}_{2}$ distribution is highly heterogeneous ${ }^{24}$ leaving open the possibility of microscopic hypoxic domains as opposed to homogeneous $\mathrm{pO}_{2}$ decrease.

Here we study age-related changes in brain tissue oxygenation within the barrel cortex of healthy, awake aged mice. In addition, vascular $\mathrm{pO}_{2}$, capillary flow and non-capillary blood flow parameters were measured to investigate the underlying vascular substrates for observed tissue oxygenation changes.

\section{Results}

Aging is associated with lower oxygenation of cerebral arterioles and venules. We first performed direct measurements of vascular $\mathrm{pO}_{2}$ in penetrating arterioles and venules of young (6-8 month-old), middle-aged (13-15 month-old) and old (24-26 month-old) mice ( $\mathrm{n}=8$ in each) using two-photon phosphorescence lifetime microscopy ${ }^{24}$ (Fig. 1a, Supplementary Fig. 1a) and intravascular injection of the $\mathrm{O}_{2}$-sensitive two-photon enhanced phosphorescent dye PtP-C $343^{25}$. All measurements were performed in awake mice on a treadmill wheel (Supplementary Fig. 1b) to avoid possible age-related anesthesia confounds. Cerebral imaging was performed through thinned-skull cranial window preparations ${ }^{26}$. We observed reduced oxygenation levels in both arterioles and venules with age, which was aggravated and reached statistical significance after middle-age (Fig. 1b,c). Average $\mathrm{pO}_{2}$ in diving arterioles was $94.7 \pm 4.0,86.9 \pm 3.9$ and $75.0 \pm 4.0 \mathrm{mmHg}$ in young, middle-aged and old mice, respectively. Average $\mathrm{pO}_{2}$ in ascending venules was $62.9 \pm 3.2$ (young), $58.1 \pm 2.7$ (middle-aged) and 49.9 \pm 2.1 (old) mmHg. Oxygen extraction fraction (OEF) was higher in the old mice (Fig. 1d), which correlates with measurements acquired in human studies performed with MRI and PET ${ }^{27-29}$.

Arterial oxygen saturation $\left(\mathrm{SpO}_{2}\right)$ measured via the tail using pulse oximetry also showed a decreasing trend (Fig. 1e). This conveys a global decrease in arterial oxygenation with age, which was magnified in smaller 
a

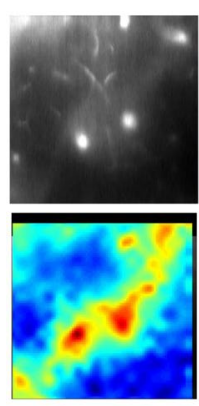

e

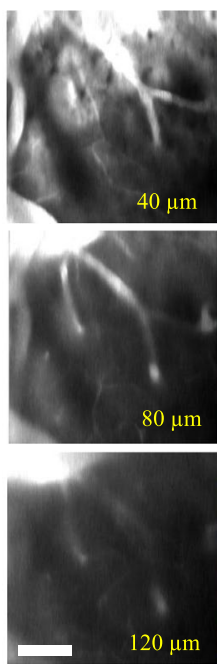

b

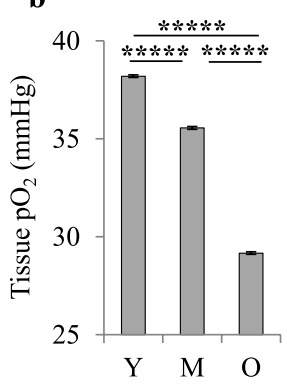

c

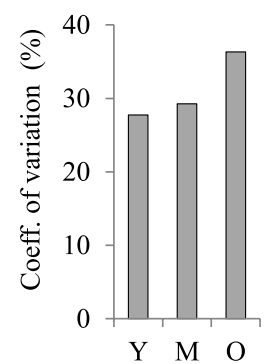

d

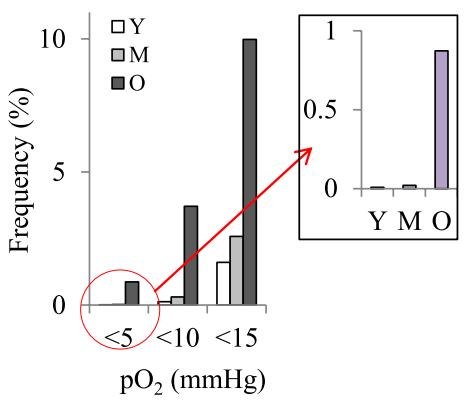

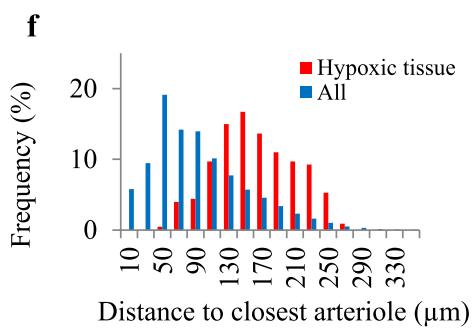

g

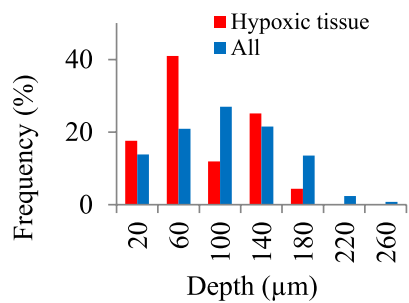

Figure 2. Compromised cerebral tissue oxygenation in old ages. (a) A representative $\mathrm{pO}_{2}$ grid over a $400 \mu \mathrm{m} \times 400 \mu \mathrm{m}$ region at the depth of $130 \mu \mathrm{m}$; top-left: fluorescent image showing the vasculature, top-right: $\mathrm{pO}_{2}$ grid measurements, bottom-left: interpolation of $2 \mathrm{D}$ grid image, bottom-right: contour plots of bottomleft image. (b) Average tissue $\mathrm{pO}_{2}$ decreased with age $(\mathrm{Y}, \mathrm{n}=27037$ sampled points from 7 mice; $\mathrm{M}, \mathrm{n}=23549$ sampled points from 6 mice; $\mathrm{O}, \mathrm{n}=25974$ sampled points from 7 mice). The bars represent mean \pm s.e.m. Statistical significance was calculated using ANOVA followed by Tukey HSD post hoc test. *****p $<0.00001$. (c) Spatial heterogeneity of $\mathrm{pO}_{2}$ distribution in tissue (defined as coefficient of variation $=\mathrm{SD} /$ mean) increased with age. (d) The percentage of sampled points with low $\mathrm{pO}_{2}$ increased with age. In young $(\mathrm{Y})$ and middleaged $(\mathrm{M})$ mice, percentage of hypoxic points $\left(\mathrm{pO}_{2}<5 \mathrm{mmHg}\right)$ is negligible, but in old $(\mathrm{O})$ animals, about $1 \%$ of sampled points are hypoxic (inset figure). (e) Two examples of hypoxic micro-pockets (marked with red lines) observed in old mice. We found hypoxic tissue in 3 old mice (out of 7 imaged old mice). The scale bar is $100 \mu \mathrm{m}$. (f) Distribution of the distance of sampled points to closest arteriole for all points and hypoxic points $\left(\mathrm{pO}_{2}<5 \mathrm{mmHg}\right.$ ) in old group, showing a negative correlation between the chance of hypoxia and distance to closest arteriole. (g) Distribution of the depth of sampled points for all points and hypoxic points $\left(\mathrm{pO}_{2}<5 \mathrm{mmHg}\right)$ in old group, showing no clear correlation between the chance of hypoxia and depth. Y: young, M: middle-aged, O: old.

arterioles of cerebral tissue potentially due to a high oxygen consumption rate. Age-related decline in arterial $\mathrm{pO}_{2}$ has also been reported in human studies ${ }^{30-32}$. Lower arterial oxygenation in older mice correlated with a decrease in systemic hematocrit (Fig. 1f), although disturbed alveolar capillary gas exchange in older subjects due to altered respiratory mechanics, pulmonary ventilation/perfusion mismatch and increased alveolar dead space has also been suggested to play a role ${ }^{30,32}$

Brain tissue $\mathrm{pO}_{2}$ decreases with age and becomes spatially more heterogeneous. The $3 \mathrm{D}$ distribution of $\mathrm{pO}_{2}$ in cerebral tissue was imaged in a separate batch of mice ( 7 young (8-9 month-old), 6 middle-aged (15-16 month-old) and 7 old (26-28 month-old)) up to a depth of $250 \mu \mathrm{m}$ (Fig. 2a). For tissue measurements, the PtP-C343 dye was slowly injected into the brain tissue, rather than by intravascular injection.

Average tissue $\mathrm{pO}_{2}$ decreased with age, with a more substantial decline after middle-age (Fig. 2b). Average tissue $\mathrm{pO}_{2}$ was $38.2 \pm 0.1,35.6 \pm 0.1$ and $29.2 \pm 0.1 \mathrm{mmHg}$ in young, middle-aged and old mice, respectively. The decrease in average tissue $\mathrm{pO}_{2}$ correlated with arteriolar $\mathrm{pO}_{2}$ (Fig. 1b,c) with a similar trend. However, changes in the capillary network and microvascular blood flow also played a role in the altered microscopic distribution of oxygen in tissue with aging (see below). Lower average tissue $\mathrm{pO}_{2}$ was also associated with increased spatial 
heterogeneity of $\mathrm{O}_{2}$ distribution in the old mice (Fig. 2c), which could originate from capillary network dysfunction making the aged brain susceptible to tissue hypoxia in micro-domains.

Evidence for the presence of hypoxic micro-pockets in the aged cortex. We then investigated if old animals with a lower and more heterogeneous cerebral tissue $\mathrm{pO}_{2}$ develop hypoxic regions. Reported values in the literature for critical tissue $\mathrm{pO}_{2}$ range from $0.01-9 \mathrm{mmHg}$, with the majority of values between $1-5 \mathrm{mmHg}^{33}$. Thus, when seeking pockets of hypoxia, we used $\mathrm{pO}_{2}<5 \mathrm{mmHg}$ as a strong indicator that tissue is at, or approaching, pathologically low oxygenation. Although the exact $\mathrm{pO}_{2}$ value which induces neuronal injury is not well defined, this arbitrary definition indicates a potential risk of such injury. Investigation of the data revealed that old mice had a higher frequency of sampled points with low $\mathrm{pO}_{2}$ (Fig. $2 \mathrm{~d}$ ) with almost $1 \%$ of the points that were hypoxic (Fig. 2d, inset). On the other hand, the number of hypoxic sampled points was negligible in the young and middle-aged mice. We then investigated the spatial organization of these hypoxic points. In old mice, low $\mathrm{pO}_{2}$ points were co-localized in the form of hypoxic micro-pockets with a size reaching up to $200 \mu \mathrm{m}$ in some regions (Fig. 2e). No hypoxic micro-pockets were detected in young or middle-aged mice. Analysis of the distances of these hypoxic points to the closest arterioles and their depth showed that they occur more often far from arterioles (Fig. 2f), in the capillary bed, but there was no correlation with depth (Fig. 2g).

Changes in non-capillary blood flow with aging. Blood flow in non-capillary vessels (diameter $>10 \mu \mathrm{m}$ ) was studied using Doppler Optical Coherence Tomography (OCT) ${ }^{34}$ (Supplementary Fig. 1f and Fig. 3) in mice from both vascular and tissue $\mathrm{pO}_{2}$ experiments $(\mathrm{n}=14,14$ and 15 for young, middle-aged and old groups, respectively). As expected, the total blood flow values obtained from penetrating arterioles and venules were almost equal (Fig. 3e, column 5). An inverted U-shaped trend, increase from young to middle-age and decrease thereafter, was observed in all flow parameters (Fig. 3e) although the trend was very weak for blood velocity and flow in individual vessels and did not reach statistical significance in all cases. Most importantly, we observed a clear inverted U-shaped trend in total blood flow which reached statistical significance for arterioles. This inverted $U$-shaped trend in total flow originated mainly from the higher surface area of the vessels at middle-age (Fig. 3e, column 4), which resulted from increased vascular diameter (Fig. 3e, column 1), and not the number of vessels (Supplementary Fig. 2).

CBF estimates from average arteriolar and venular flow maps were $1.7 \pm 0.4,2.3 \pm 0.4$ and $1.9 \pm 0.4 \mathrm{ml} / \mathrm{g} / \mathrm{min}$ for young, middle-aged and old mice, respectively (Fig. 3f). Estimated CBF followed an inverted U-shaped trend with age which did not reach statistical significance. Three previous studies using the same method reported a $\mathrm{CBF}$ of $\sim 0.6 \mathrm{ml} / \mathrm{g} / \mathrm{min}$ in anesthetized young $\mathrm{rats}^{34}$ and $0.5-2.0 \mathrm{ml} / \mathrm{g} / \mathrm{min}$ in anesthetized young mice under varying conditions ${ }^{35,36}$. One study using the quantitative autoradiographic iodo[14 C]antipyrine method obtained a CBF value of $\sim 0.7 \mathrm{ml} / \mathrm{g} / \mathrm{min}$ for the barrel field of anesthetized young rats, but CBF was $\sim 1.8 \mathrm{ml} / \mathrm{g} / \mathrm{min}$ under awake conditions ${ }^{37}$, which is in agreement with our CBF estimate in the barrel cortex of young mice.

Interestingly, heart rate (HR, extracted from pulse oximetry data) and body weight of the animals also followed the same inverted U-shaped trend (Fig. 3g,h). Data from Barsha et al. also shows that in awake, non-restrained mice, HR follows an inverted U-shaped trend from 3 to 18 months of age, peaking at 14 months ${ }^{38}$. A number of studies on mice ${ }^{39}$, monkeys ${ }^{40}$ and humans ${ }^{41}$ have shown that cardiac output (CO) is directly linked to HR. Therefore, the observed increase in $\mathrm{HR}$ at middle-age suggests increased $\mathrm{CO}$, which is necessary to support a higher demand for oxygen and other nutrients in middle-aged mice having a larger body mass. Indeed, a study found lower $\mathrm{CO}$ in 2-month-old rats compared with 6-and 24-month-old rats, but CO normalized to total body mass was not different among age groups ${ }^{42}$. We also observed that HR normalized to the body weight did not differ in our age groups (Supplementary Fig. 3a). A higher CO at middle-age correlated with the higher total observable brain arterial flow.

Capillary network remodeling from young to middle-age maintains capillary bed tissue $\mathrm{pO}_{2}$ despite lower tissue $\mathrm{pO}_{2}$ adjacent to arterioles. Red blood cell (RBC) flow in capillaries (diameter $<10 \mu \mathrm{m}$ ) was imaged using two-photon laser-scanning fluorescence microscopy (Supplementary Fig. 1a and Fig. $4 \mathrm{a}, \mathrm{b})^{43,44}$. Capillary flow measurements (30-40 capillaries per animal) were performed on the mice in which vascular $\mathrm{pO}_{2}$ was imaged $(\mathrm{n}=8,7$ and 8 for young, middle-aged and old groups, respectively).

From young to middle-age, there was no significant change in capillary diameter, flow, and hematocrit (Fig. 4c,f,g), but RBC flux and speed were reduced (Fig. 4d,e). Since total flow tended to increase from young to middle-age (Fig. 3e), this observation suggests increased capillary density at middle-age such that slightly higher blood flow is distributed into a larger number of capillaries. Using the CBF measure over the same region and assuming a simplified model we evaluated this hypothesis (Fig. 4j). In this model, we assumed that the imaged cortical volume was fed and drained by a single arteriole and venule, and that the capillary network consisted of parallel straight tubes with uniform length and diameter connecting the arteriole to the venule. Mass conservation states that total flow into and out of the imaged volume (CBF) should be equal to the average volumetric capillary flow multiplied by the number of capillaries. Although far from reality, the model provides a rough estimation of the relative capillary densities between the age groups. Estimated capillary densities (Fig. 4j) showed an increasing trend from young to middle-age, which did not reach statistical significance. We then calculated the capillary density from two-photon fluorescent angiograms (Fig. 4k). Capillary density at middle-age was higher when compared with the young age at most depths in the range $0-150 \mu \mathrm{m}$, which reached statistical significance $(\mathrm{p}<0.05)$ through the depths of $\sim 25-55 \mu \mathrm{m}$ and approached significance through the depths of $\sim 75-90 \mu \mathrm{m}$ (Fig. 4l).

Since from young to middle-age, hematocrit did not change (Fig. 4g) and there was no increase in spatial heterogeneity of RBC speed (Fig. 4i) (as an indirect measure of capillary transit time heterogeneity (CTTH) which has been suggested to affect the oxygen extraction efficiency from the capillary network ${ }^{45,46}$ ) a denser capillary 


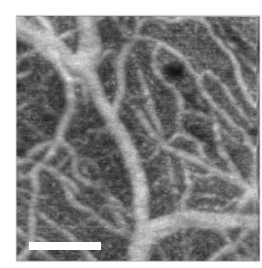

b

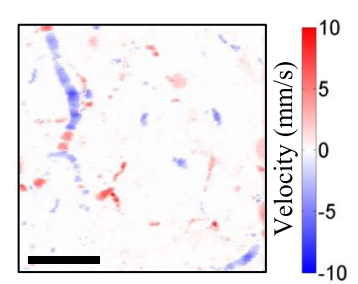

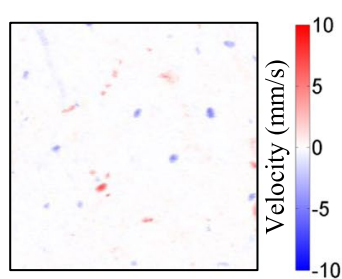

d

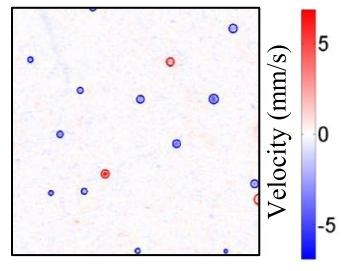

$\mathbf{e}$

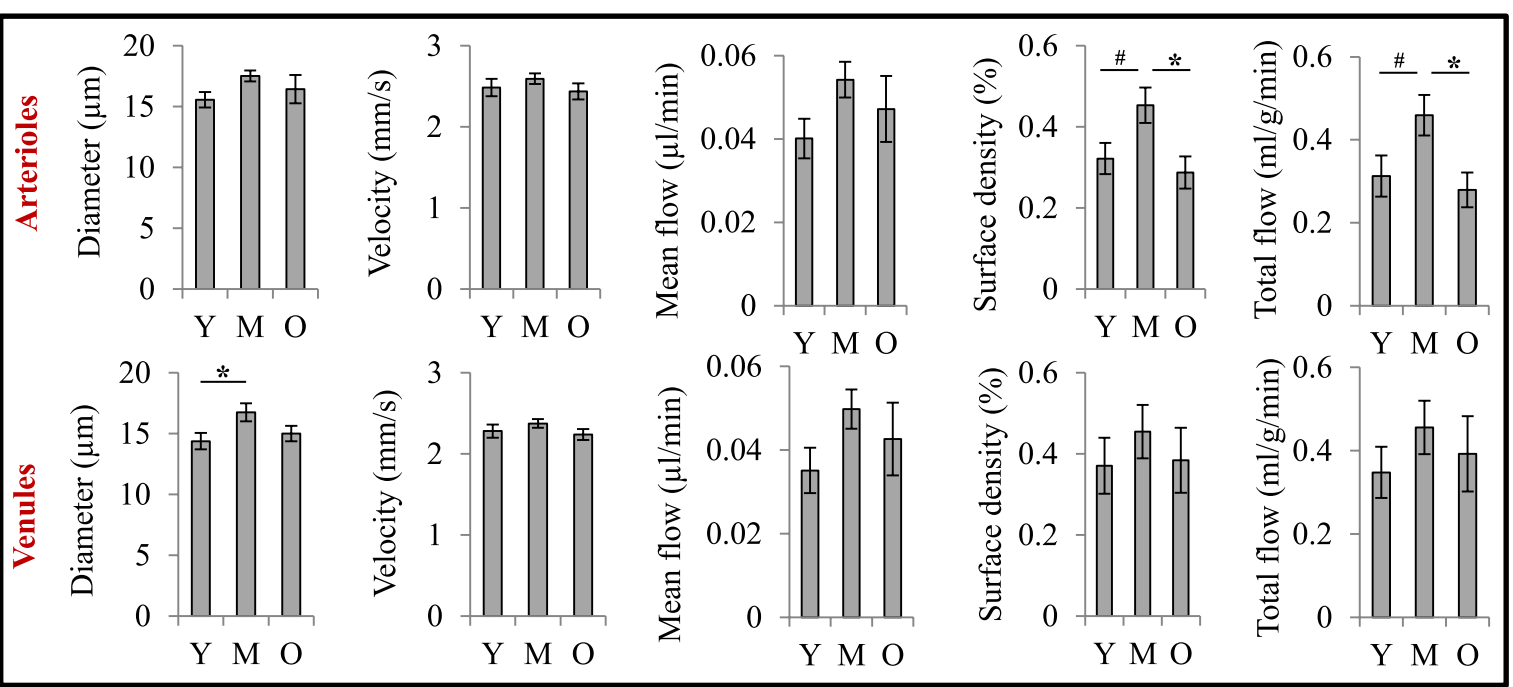

f

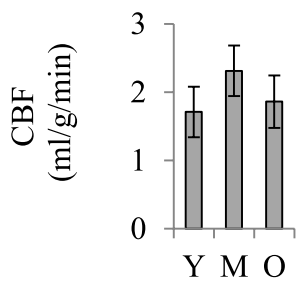

g

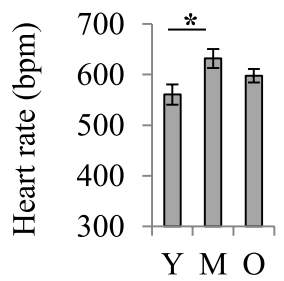

h

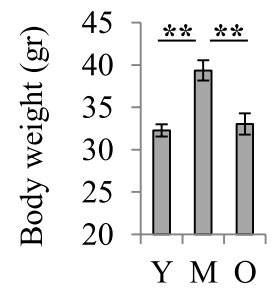

Figure 3. Non-capillary blood flow. (a) En face maximum intensity projection (MIP) of a 3D OCT angiogram through the depth of $0-650 \mu \mathrm{m}$. The scale bar is $200 \mu \mathrm{m}$. (b) En face MIP of a 3D OCT velocity volume through the depth of $0-650 \mu \mathrm{m}$, on the same region as in (a). Positive velocity represents downward flow (arterioles) and negative velocity represents upward flow (venules). The shifts in flow direction in surface vessels are due to their curved path. (c) En face MIP of a 3D OCT velocity volume through the depth of 50-100 $\mu \mathrm{m}$, on the same region as in (a). The top $50 \mu \mathrm{m}$ volumes were excluded to remove the surface vessels. Only $50 \mu \mathrm{m}$ of depth just below the surface vessels was included for the estimation of total blood flowing into or out of brain in the imaged region. (d) An en face slice through the OCT velocity volume at a cortical depth of approximately $70 \mu \mathrm{m}$, over the same region as in (a). For each slice in the OCT velocity volume, arterioles and venules were detected (red and blue circles) and their diameter, average velocity and flow were obtained. The summation of flow and crosssection area of individual vessels over the slice yielded the total arterial or venular flow and the surface densities of vessels over the region at each depth. (e) Diameter, velocity and flow of individual vessels detected in the slices of the OCT velocity volume, as well as total arterial and venular flow and surface densities were averaged through the depth of $50-650 \mu \mathrm{m}$ to yield the mean values over the imaged region in each animal. Top $50 \mu \mathrm{m}$ cortical layer was excluded to remove surface vessels (top row: arterioles; bottom row: venules). (f) For each animal, arterial and venular total flows, averaged through the depth of 50-100 $\mu \mathrm{m}$, were averaged as an estimate of regional CBF. (g) Heart rate, extracted from pulse oximetry data. (h) Body weight. Y: young $(\mathrm{n}=14)$, M: middle-aged $(\mathrm{n}=14)$, O: old $(\mathrm{n}=15)$. Bar plots represent mean \pm s.e.m. Statistical significance was calculated using ANOVA followed by Tukey HSD post hoc test. **p $<0.01,{ }^{*} \mathrm{p}<0.05$, ${ }^{*} \mathrm{p}$-value approaches significance $(\mathrm{p}<0.1)$.

network at middle-age is hypothesized to be able to deliver the same amount of oxygen to the tissue by a smaller $\mathrm{pO}_{2}$ gradient (between the capillaries and tissue). This smaller gradient leads to unchanged tissue $\mathrm{pO}_{2}$ from young to middle-age despite a decrease in intravascular $\mathrm{pO}_{2}$, provided that $\mathrm{CMRO}_{2}$ does not change significantly (see below). Interestingly, regional analysis of tissue $\mathrm{pO}_{2}$ data confirmed this conclusion. We observed that tissue $\mathrm{pO}_{2}$ near arterioles declines continuously with age, but distant from the arterioles (in the capillary bed) tissue $\mathrm{pO}_{2}$ is maintained until middle-age followed by a significant decrease afterwards (Fig. 5). 

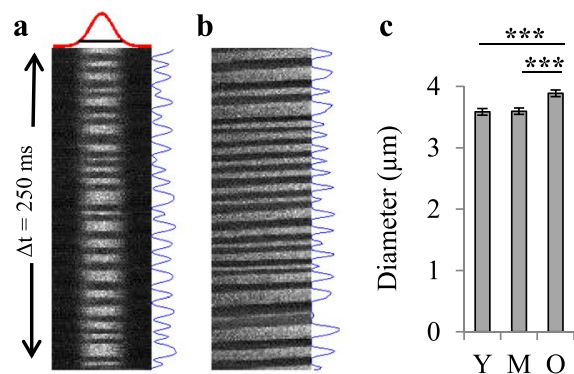

h

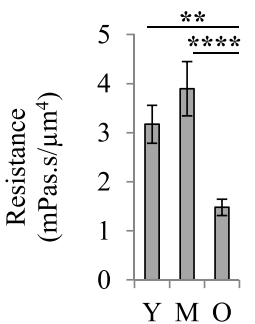

i

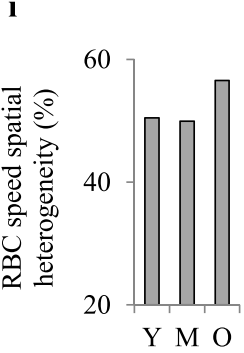

$\mathbf{k}$

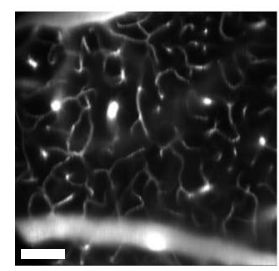

d

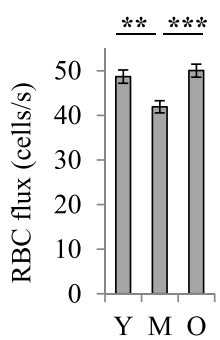

e

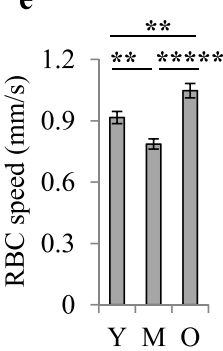

f

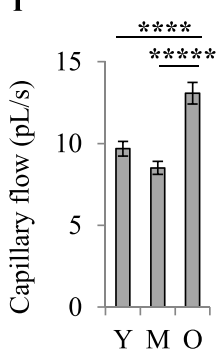

g

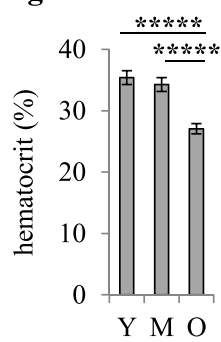

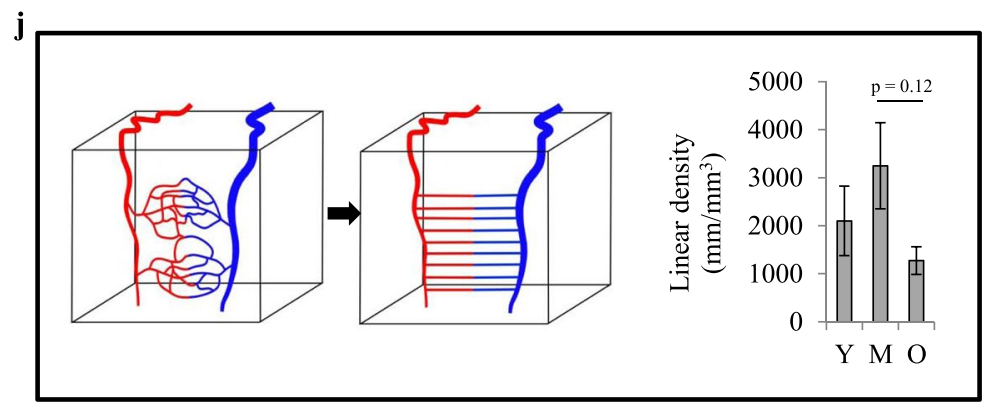

I

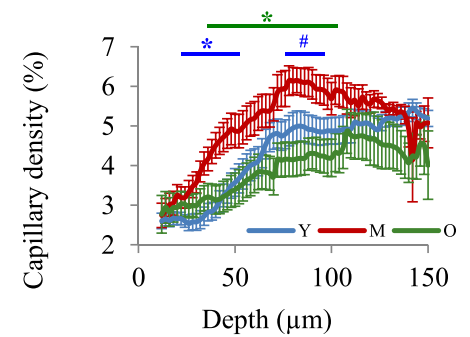

m

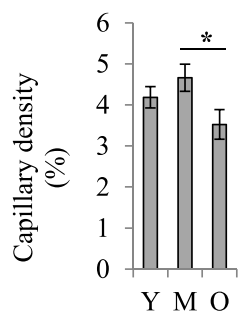

Figure 4. Capillary blood flow. (a) A representative space-time image from perpendicular scans. The image was averaged in vertical direction and fitted with a Gaussian function (top) to estimate the capillary diameter. The image was also averaged in horizontal direction (right) to find the number of passing RBCs. (b) A representative space-time image from longitudinal scans. RBC velocity was calculated from the angle of dark streaks. The image was rotated by this angle and averaged (right) to find the number of passing RBCs. (c-g) Capillary diameter (c), RBC flux (d) and RBC speed (e) were obtained from space-time images. Capillary volumetric flow (f) and hematocrit (g) were calculated from diameter, flux and speed ( $\mathrm{Y}, \mathrm{n}=242 ; \mathrm{M}, \mathrm{n}=252 ; \mathrm{O}, \mathrm{n}=278$ capillaries). (h) Capillary resistance was estimated from diameter and hematocrit. (i) Spatial heterogeneity (defined as the coefficient of variation) of RBC speed. (j) For the mice that both flow in large vessels and capillary flow were measured over the same region $(\mathrm{Y}, \mathrm{n}=8 ; \mathrm{M}, \mathrm{n}=7 ; \mathrm{O}, \mathrm{n}=8$ mice), capillary linear density was estimated (right) by simplifying the capillary network architecture as straight tubes with uniform length and diameter connecting an arteriole to a venule (left). (k) Microvascular angiograms were used to directly obtain the capillary density. Left: an en face slice at the depth of $\sim 80 \mu \mathrm{m}$ (scale bar: $100 \mu \mathrm{m}$ ). Middle: binarization of the left image. Right: the same as middle image, but processed with a median filter to remove the fine structures (capillaries). (1) Capillary density (volume\%) versus depth obtained from angiograms by subtracting the density of large vessels from total vascular density. The blue * (or \#) represents statistically significant (or nearly significant) differences between $\mathrm{Y}$ and $\mathrm{M}$. The green * represents statistically significant differences between $\mathrm{M}$ and $\mathrm{O}$. (m) Average capillary density through the depth of $0-150 \mu \mathrm{m}(\mathrm{Y}, \mathrm{n}=18 ; \mathrm{M}, \mathrm{n}=15 ; \mathrm{O}, \mathrm{n}=16$ angiograms). Results are presented as mean \pm s.e.m. Statistical significance was calculated using ANOVA followed by Tukey HSD post hoc test. *****p $<0.00001, * * * * \mathrm{p}<0.0001, * * * \mathrm{p}<0.001, * * \mathrm{p}<0.01,{ }^{*} \mathrm{p}<0.05$, ${ }^{\#} \mathrm{p}$-value approaches significance $(\mathrm{p}<0.1)$. Y: young $(8 \mathrm{mice}), \mathrm{M}$ : middle-aged (7 mice), O: old ( 8 mice).

There is conflicting data in the literature regarding $\mathrm{CMRO}_{2}$ changes with age; while a few studies found increased $\mathrm{CMRO}_{2}$ with age ${ }^{27,29}$, most studies report a decrease or no change in $\mathrm{CMRO}_{2}{ }^{28,47-49}$. Here, since for each animal we had the measures of arteriolar and venular $\mathrm{pO}_{2}$ and also recorded CBF over the same region, it was possible to estimate $\mathrm{CMRO}_{2}$ of the imaged volume for individual mice (Fig. 6a). Estimated $\mathrm{CMRO}_{2}$ did not change significantly with age (Fig. 6a), supporting our delivery assumptions above.

Next, we investigated the $\mathrm{O}_{2}$ delivery to tissue by capillaries to assess our hypothesis of unaltered total capillary $\mathrm{O}_{2}$ supply from young to middle-age. In rats, it was shown that fitting the tissue $\mathrm{pO}_{2}$ profiles from diving arterioles with the Krogh cylinder model of $\mathrm{O}_{2}$ diffusion ${ }^{50}$ (Fig. 6b) yields a measure of $\mathrm{CMRO}_{2}{ }^{51}$. This method was based on the fact that, in rats, there is a capillary depleted region around arterioles ${ }^{33}$ and tissue $\mathrm{pO}_{2}$ profiles plateau mainly within this region. Thus, the $\mathrm{O}_{2}$ consumption term in the Krogh model is solely representative of $\mathrm{CMRO}_{2}$. 
a

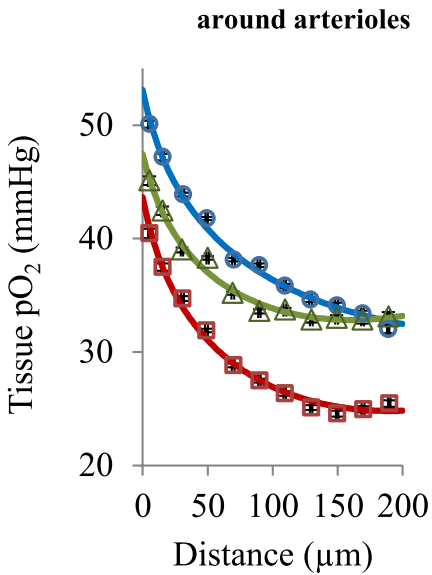

around venules

b
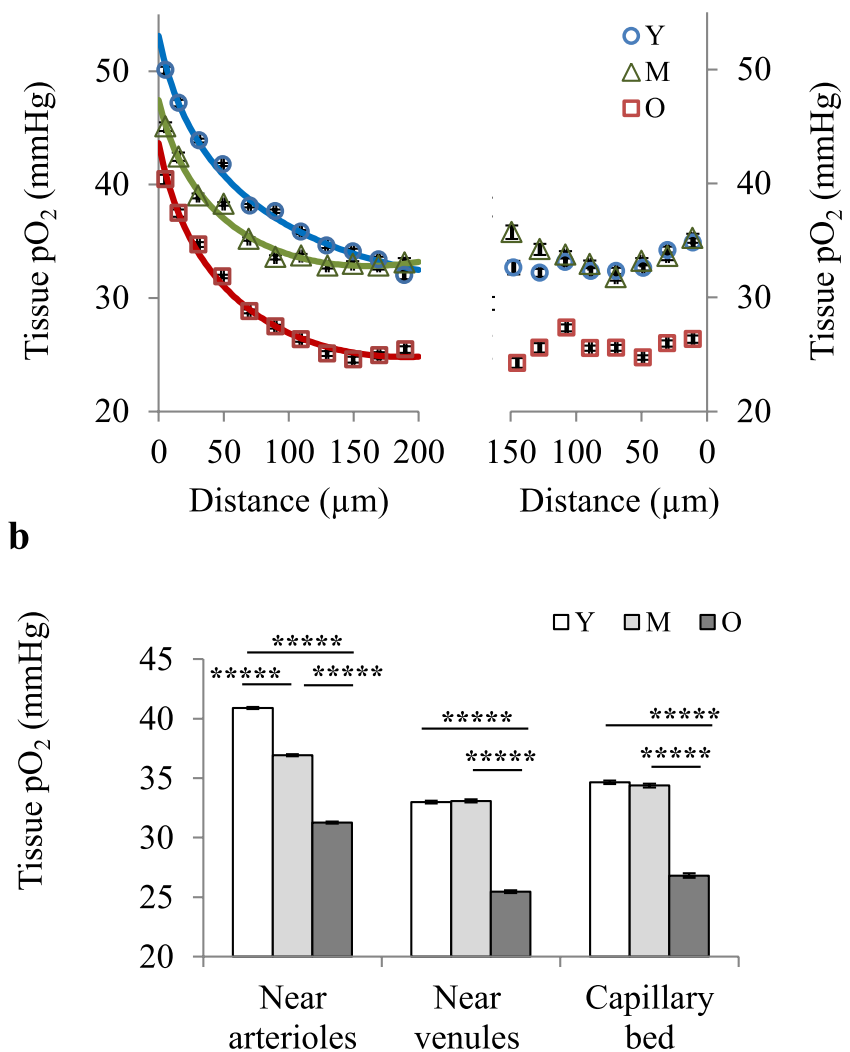

Figure 5. Region-specific tissue oxygenation changes with age. (a) For each sampled $\mathrm{pO}_{2}$ point, the distance to closest arteriole and venule was obtained. All sampled points in each age group were then pooled and plotted versus distance from closest arteriole or venule to obtain average tissue $\mathrm{pO}_{2}$ gradients around arterioles (left) and venules (right). Results are presented as mean \pm s.e.m. (b) Average tissue $\mathrm{pO}_{2}$ in three defined regions: near arterioles ( $<100 \mu \mathrm{m}$ from an arteriole; $\mathrm{Y}, \mathrm{n}=17052 ; \mathrm{M}, \mathrm{n}=13971 ; \mathrm{O}, \mathrm{n}=16240$ sampled points), near venules $(<100 \mu \mathrm{m}$ from a venule, but $>100 \mu \mathrm{m}$ from closest arteriole; $\mathrm{Y}, \mathrm{n}=6212 ; \mathrm{M}, \mathrm{n}=6001 ; \mathrm{O}, \mathrm{n}=7834$ sampled points), and in capillary bed ( $>100 \mu \mathrm{m}$ from arterioles or venules; $\mathrm{Y}, \mathrm{n}=3773 ; \mathrm{M}, \mathrm{n}=3577 ; \mathrm{O}, \mathrm{n}=1951$ sampled points). Results are presented as mean \pm s.e.m. Statistical significance was calculated using ANOVA followed by Tukey HSD post hoc test. *****p $<0.00001$. Y: young (7 mice), M: middle-aged (6 mice), O: old (7 mice).

However, in mice we either do not see capillary depleted regions around arterioles or they are smaller than the distance at which the tissue $\mathrm{pO}_{2}$ profiles from arterioles plateau (Fig. 6d). Therefore, Krogh fitting in mice yields a net oxygen consumption rate (OC), which we defined as $\mathrm{CMRO}_{2}$ minus the rate of oxygen supply by capillaries (Fig. 6c). Tissue $\mathrm{pO}_{2}$ profiles around arterioles, obtained from tissue $\mathrm{pO}_{2}$ maps, were fitted with the Krogh model (Fig. 6e) to obtain the $\mathrm{OC}$ and $\mathrm{R}_{\mathrm{t}}$ (the radius of equivalent cylinder supplied by the arteriole). No significant change in $\mathrm{OC}$ and $\mathrm{R}_{\mathrm{t}}$ or their spatial heterogeneities was observed between young and middle-aged mice (Fig. 6f). Since OC and $\mathrm{CMRO}_{2}$ did not change significantly from young to middle-age, it supports the conclusion that overall capillary $\mathrm{O}_{2}$ supply remains unchanged.

Impaired capillary function in old mice could be largely responsible for more heterogeneous tissue $\mathrm{pO}_{2}$ and the presence of hypoxic micro-pockets. Capillary flow imaging showed that from middle-age to old age there was an increase in RBC flux, RBC speed and capillary flow (Fig. 4d,e,f). Higher RBC flow in old age has been also reported before in anesthetized mice ${ }^{43}$ and rats ${ }^{44}$. Since total flow decreased from middle-age to old age (Fig. 3e), this observation can only be explained by decreased capillary density. Estimated capillary density from CBF and capillary flow data using the simplified parallel capillary tubes model explained above showed a decreasing trend from middle-age to old age, (Fig. 4j). The capillary density calculated from two-photon fluorescent angiograms then provided supporting evidence for decreased density after middle-age (Fig. 4l,m).

We observed an increase in the capillary diameter in the old mice compared with the middle-aged and young animals (Fig. 4a), suggesting a dilation of capillaries to allow a higher capillary flow due to fewer capillaries delivering oxygen. Also, in agreement with lower systemic hematocrit in old mice (Fig. 1f), capillary hematocrit decreased after middle-age (Fig. 4g). The combined effect of decreased hematocrit and increased diameter in old animals reduced the capillary resistance (Fig. $4 \mathrm{~h}$ ) and supported the higher capillary flow.

Finally, we observed increased RBC speed spatial heterogeneity in old mice, which reflects higher CTTH. Thus, the combined effect of higher CTTH, lower hematocrit, lower capillary density and lower vascular $\mathrm{pO}_{2}$ 
a

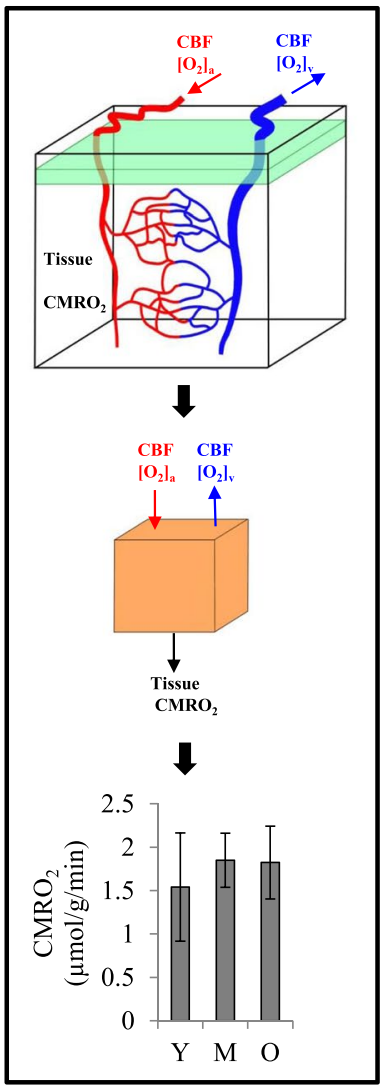

b

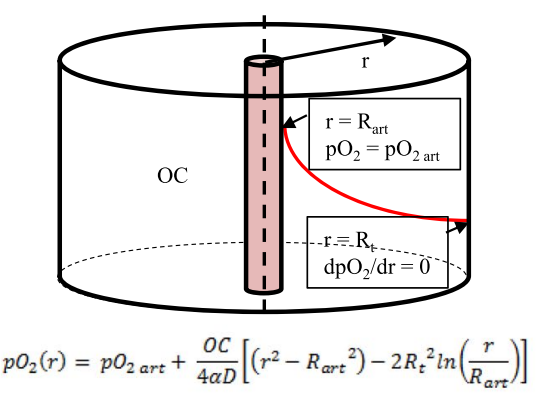

c
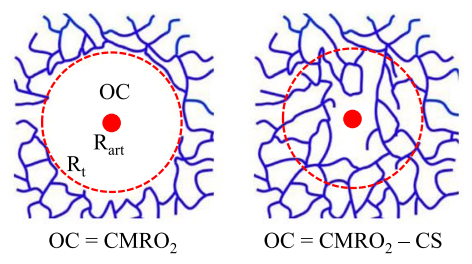

d

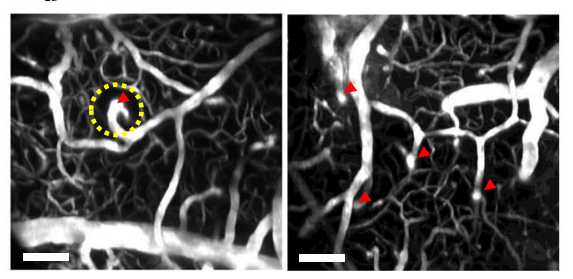

e

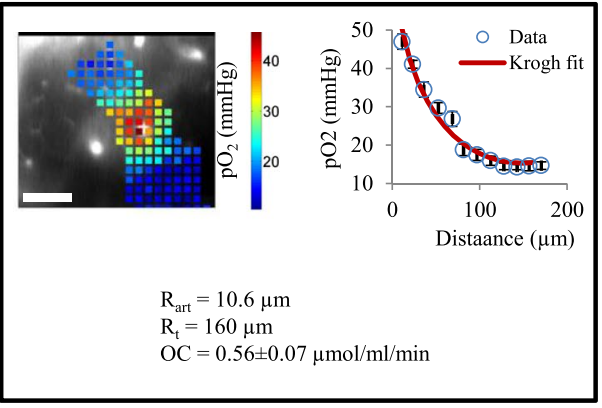

$\mathbf{f}$

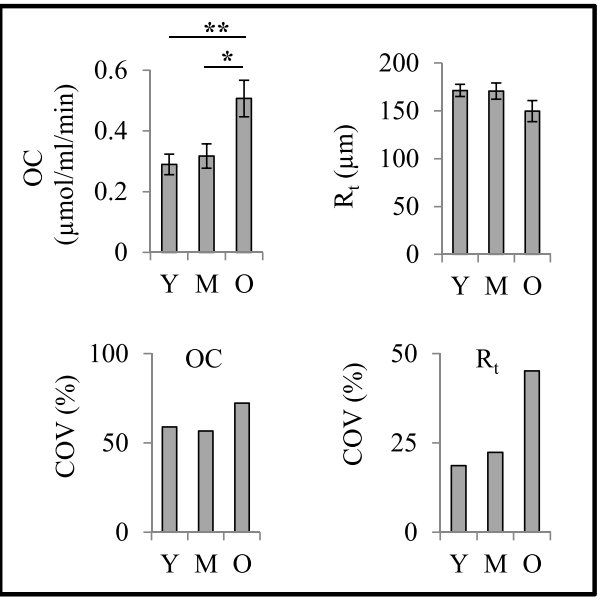

Figure 6. Estimation of cerebral metabolic rate of oxygen consumption $\left(\mathrm{CMRO}_{2}\right)$ and net oxygen consumption rate (OC) in tissue. (a) $\mathrm{CMRO}_{2}$ was obtained using the equation $\mathrm{CMRO}_{2}=\mathrm{CBF}\left(\left[\mathrm{O}_{2}\right]_{\mathrm{a}}-\left[\mathrm{O}_{2}\right]_{\mathrm{V}}\right)$ for the mice that both vascular $\mathrm{pO}_{2}$ and blood flow in large vessels were measured over the same region $(\mathrm{Y}, \mathrm{n}=8 ; \mathrm{M}, \mathrm{n}=7 ; \mathrm{O}$, $\mathrm{n}=7$ mice). (b) The Krogh cylinder model of $\mathrm{O}_{2}$ diffusion from a vessel to surrounding tissue. This model assumes that an infinitely long arteriole with radius $\mathrm{R}_{\text {art }}$ supplies an infinitely long tissue cylinder with radius $\mathrm{R}_{\mathrm{t}}$. Continuity equation for $\mathrm{O}_{2}$ is solved assuming a uniform net oxygen consumption rate (OC) in tissue cylinder with specified boundary conditions. (c) If there is a capillary depleted cylinder around arterioles and the major tissue $\mathrm{pO}_{2}$ gradient around arterioles occurs within this region, OC term in Krogh model will be a good estimate of $\mathrm{CMRO}_{2}$ (left). But if the capillary depleted region is much smaller than $\mathrm{R}_{\mathrm{t}}$, OC represents the difference between $\mathrm{CMRO}_{2}$ and capillary $\mathrm{O}_{2}$ supply (CS) (right). (d) Examples of the maximum intensity projection of microvascular angiograms showing diving arterioles (arrow heads) with (left) and without (right) a capillary depleted region; in mice the absence of capillary depleted regions around some arterioles was observed. Even in cases where a capillary depleted region existed, its radius did not exceed $50 \mu \mathrm{m}$, while tissue $\mathrm{pO}_{2}$ profiles often saw a significant $\mathrm{pO}_{2}$ drop up to $100 \mu \mathrm{m}$ from arterioles. (e) $2 \mathrm{D}$-grid point measurements around arterioles (left) yielded $\mathrm{pO}_{2}$ gradients from arterioles which were fitted with the Krogh model to obtain OC (right). (f) $\mathrm{OC}$ and $\mathrm{R}_{\mathrm{t}}$ were found for individual vessels and were averaged in each age group (top). Spatial heterogeneity of OC and $R_{t}$ were estimated by the coefficient of variation (bottom) $(Y, n=26$ arterioles from 5 mice; $M, n=20$ arterioles from 5 mice; $O, n=37$ arterioles from 7 mice). Y: young, M: middle-aged, O: old. Scale bars are $100 \mu \mathrm{m}$. Bar plots represent mean \pm s.e.m. Statistical significance was calculated using ANOVA followed by Tukey HSD post hoc test. **p $<0.01 * \mathrm{p}<0.05$.

levels in the old animals can substantially reduce the capillary $\mathrm{O}_{2}$ delivery efficiency and could be largely responsible for the significant decrease in tissue $\mathrm{pO}_{2}$ (Fig. 5), increased spatial heterogeneity of tissue oxygenation (Fig. 2c), and the presence of hypoxic micro-pockets (Fig. 2e).

Further evidence for impaired capillary $\mathrm{O}_{2}$ delivery in old animals comes from the OC estimations from the Krogh fitting, which was significantly higher in old animals (Fig. 6f). Considering no significant change in $\mathrm{CMRO}_{2}$ with age (Fig. 6a), this suggests decreased capillary oxygen supply. In addition, a higher spatial heterogeneity in both $\mathrm{OC}$ and $\mathrm{R}_{\mathrm{t}}$ was observed (Fig. 6f), which suggests a more heterogeneous oxygen supply by capillaries which is in line with our observations of more heterogeneous tissue oxygenation in old animals and the presence of hypoxic micro-pockets.

Shifted fractional contribution of arterioles and capillaries in $\mathrm{O}_{2}$ delivery to cerebral tissue in old ages. Recent evidence showed that both arterioles and capillaries contribute to tissue oxygenation, although capillaries have a higher contribution $(\sim 20 \% \text { by diving arterioles })^{52,53}$. Our OC and $\mathrm{CMRO}_{2}$ values also estimate 
that $\sim 20-30 \%$ of delivered oxygen is supplied by arterioles. As discussed above, $\mathrm{CMRO}_{2}$ was not largely affected by age (Fig. 6a). Therefore, in old mice the same amount of total $\mathrm{O}_{2}$ should be delivered to the cerebral tissue as in younger animals. Since our data suggests that $\mathrm{O}_{2}$ delivery by capillaries is decreased in old mice, arterioles have to provide more oxygen to the surrounding tissue to keep the total $\mathrm{O}_{2}$ delivery unchanged.

In the mice that were measured with Doppler OCT and vascular $\mathrm{pO}_{2}$ imaging over the same region $(\mathrm{n}=8,7$ and 8 mice for young, middle-age and old groups, respectively), we could identify diving arterioles in which we had both the arterial $\mathrm{pO}_{2}$ versus depth and their blood flow (Fig. 7a). This technique provided the unique opportunity to calculate the oxygen delivered to the surrounding tissue by individual arterioles (Fig. 7b). The results showed a higher $\mathrm{O}_{2}$ delivery by individual arterioles in the old group compared with the young and middle-aged groups (Fig. 7d), confirming our hypothesis of a shift in the fractional contribution of arterioles and capillaries in tissue oxygenation towards arteriolar supply in the old mice. This shift maintains total $\mathrm{O}_{2}$ delivery, but brings more heterogeneity to tissue oxygenation. This was also coherent with the observation that hypoxic points were often away from arterioles (Fig. 2f).

\section{Discussion}

In this study, we found age-related decreases in arteriolar and tissue $\mathrm{pO}_{2}$ in the mouse cortex, which worsened after middle-age. Our data suggests that from young to middle-age capillary network remodeling maintains the capillary bed tissue $\mathrm{pO}_{2}$, despite a decreased tissue $\mathrm{pO}_{2}$ next to arterioles. However, after middle-age, oxygen delivery by the capillary network is impaired, with our data pointing to decreased hematocrit, reduced capillary density and higher CTTH as the causes. This results in a significant decrease in tissue $\mathrm{pO}_{2}$, higher spatial heterogeneity of tissue oxygenation, and the presence of hypoxic micro-pockets in old mice. Additionally, using a modified Krogh model, we could estimate the capillary oxygen supply and the shift in oxygen delivery from capillaries to arterioles after middle-age, although the larger tissue volumes underlying the $\mathrm{CMRO}_{2}$ estimates and the observed variance make a precise comparison difficult to achieve. A limitation of this study was that separate cohorts of animals were used for vascular and tissue $\mathrm{pO}_{2}$ measurements. Furthermore, cortical reads do not necessarily represent deep brain regional changes and white matter.

All measurements were done in awake mice, removing the confounding effects of anesthesia. Awake imaging is particularly important in aging studies since anesthesia may affect physiological and hemodynamic parameters differently in young and old subjects. In addition, anesthetized experiments often need mechanical ventilation and/or adjustment of physiological parameters which the results because many of these parameters normally change with aging. To minimize animal stress during imaging, a custom-built treadmill wheel was used in which the animal was able to freely walk or run, while the head was fixed, similar to that of Lyons et al..$^{54}$. No obvious difference was observed among age groups in terms of the time it takes for them to habituate to the head restrain conditions or their behavior in the cages, during handling, or on the wheel. In all three age groups, after training sessions, the mice could easily walk on the fixation wheel with no sign of stress or discomfort (e.g., grooming behavior was maintained). While we aimed to minimize confounds, our use of the probe PtP-C343 is also associated with known limitations when measuring absolute $\mathrm{pO}_{2}$ values: potential interaction with plasma proteins when doing vascular measures, temperature dependence, $\mathrm{O}_{2}$ consumption by the probe itself and background signal that increases with depth, more so in a thin-skull preparation which increases excitation light scattering. However, we have no reason to believe these confounds would differentially affect our group comparisons.

In addition to the role of hematocrit, capillary density and CTTH in decreasing tissue $\mathrm{pO}_{2}$ in old mice, a possible shift in the oxyhemoglobin dissociation curve with age can also affect the oxygen uptake in the lungs and its delivery to tissue. In human erythrocytes, it has been shown in vivo that RBC aging shifts the oxygen dissociation curve to the left ${ }^{55-57}$. However, it has been reported that the RBC age distribution does not differ in male human subgroups of different ages ${ }^{56,57}$. Investigation of the oxygen dissociation curves of blood samples from different age groups could answer the question more clearly, but we only found one human study showing a slight rightward shift of the oxyhemoglobin dissociation curve in elderly subjects ${ }^{32}$.

Our observation of hypoxic micropockets in old age could be linked to previous neuropathological findings which report that tiny microinfarcts (mean diameter $\sim 200-1000 \mu \mathrm{m})^{58}$ are very common in the brain samples from old individuals, particularly people suffering from mild cognitive decline or $\mathrm{AD}^{59}$. A causal role of these microinfarcts in age-related cognitive disorders has been suggested. An animal study also reported neuronal loss and cognitive impairment in a mouse model of multiple diffuse microinfarcts ${ }^{59}$. These and our findings support the hypothesis that impaired tissue oxygenation in healthy aging may be one of the mechanisms involved in cognition decline. Unfortunately, in our tissue $\mathrm{pO}_{2}$ images the small capillaries were not clearly visible in most cases because of the background fluorescence of the PtP-C343 dye. Therefore, it was not possible to study the correlation between hypoxia and local capillary loss. Although our data showed an overall reduction in mean capillary density and hematocrit in old mice, future studies need to be performed to correlate the hypoxic micropockets with local capillary density or capillary flow parameters, as well as local neuronal death.

The inverted U-shape relationship observed between CBF and age is against the general conception of decreased ${ }^{60}$ or unchanged $\mathrm{CBF}^{61,62}$ with age in humans. However, there are a number of studies that report either stable $\mathrm{CBF}$ until middle-age with decline thereafter ${ }^{63-66}$, or a parabolic trend in global CBF peaking at an age of $\sim 60$ years ${ }^{67}$. In anesthetized rats, CBF was also shown to decrease with age ${ }^{68,69}$, but two studies on conscious rats observed a parabolic trend, peaking between 3-14 months of age $\mathrm{e}^{70,71}$. Differences in the techniques, brain regions, the age range, the criteria for the selection of healthy old subjects and inclusion or exclusion of middle-aged subjects may account for the disparate findings. Our investigation underlines the necessity of including a middle-age group in aging studies. Our CBF estimates were obtained assuming unchanged cortical thickness with age. As a rough analysis, we normalized the $\mathrm{CBF}$ to total body weight and we observed a flatter trend in age-related change (Supplementary Fig. 3b). Although cortical thickness changes do not necessarily follow total body weight changes, this rough analysis showed that observed trends in estimated capillary density and $\mathrm{CMRO}_{2}$ were not 
$\mathbf{a}$
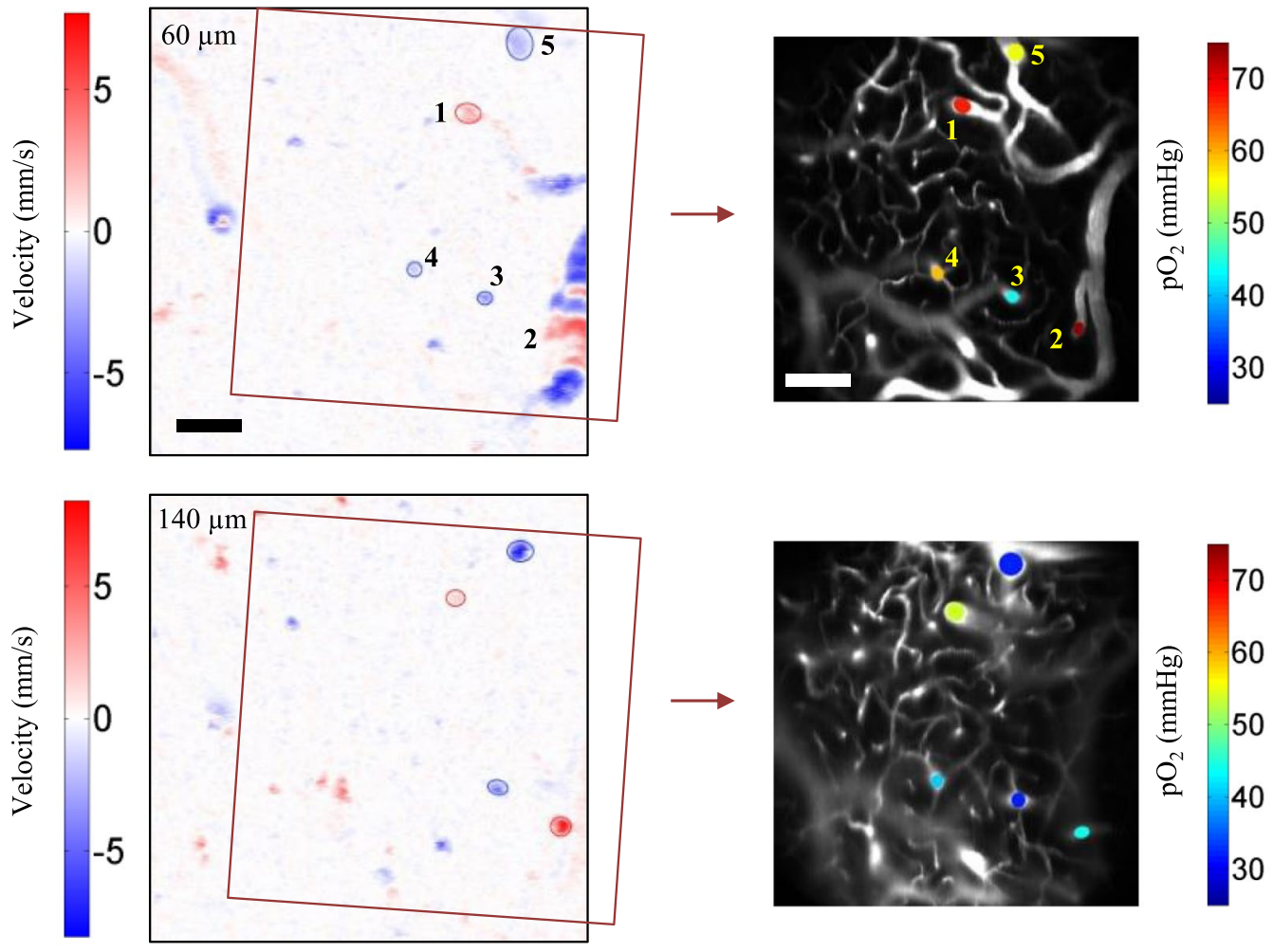

b

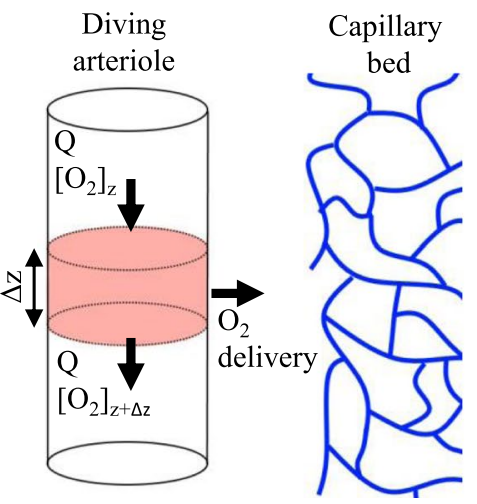

c

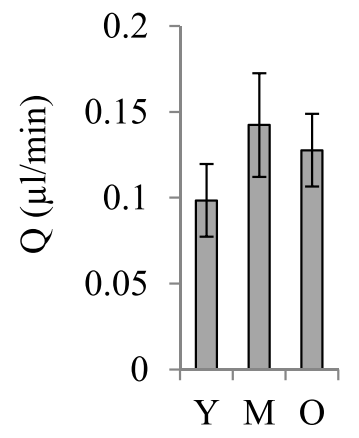

d

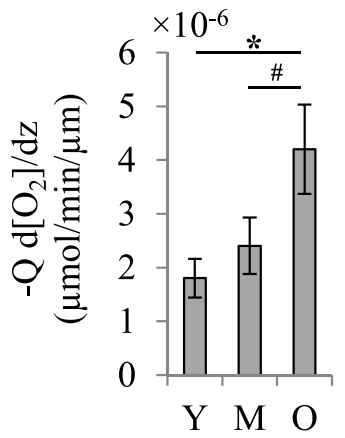

Figure 7. $\mathrm{O}_{2}$ delivery by individual arterioles. (a) Left: Two en face slices through the Doppler OCT velocity volume at cortical depths of approximately 60 and $140 \mu \mathrm{m}$. Right: En face slices through the two-photon angiogram over specified regions on OCT images (left) at the same depths, with vascular $\mathrm{pO}_{2}$ measurements superimposed (1-2: arterioles, 3-5: venules). Vascular $\mathrm{pO}_{2}$ was measured in 30-40 $\mu \mathrm{m}$ steps. Measured vessels were identified on the Doppler OCT volume and their average flow over depth was obtained. The scale bars are $100 \mu \mathrm{m}$. (b) The amount of $\mathrm{O}_{2}$ delivered to the tissue by individual arterioles can be estimated from the longitudinal gradient of $\mathrm{O}_{2}$ flow in arterioles $\left(\mathrm{O}_{2}\right.$ mass balance). (c) Average blood flow of diving arterioles. (d) $\mathrm{O}_{2}$ delivery to tissue by individual arterioles (per unit length) estimated by longitudinal gradient of $\mathrm{O}_{2}$ flow as shown in (b). Y: young ( $n=14$ arterioles from 8 mice), M: middle-aged $(n=13$ arterioles from 7 mice), O: old ( $n=11$ arterioles from 5 mice). Bar plots represent mean \pm s.e.m. Statistical significance was calculated using ANOVA followed by Tukey HSD post hoc test. ${ }^{* *} \mathrm{p}<0.01 * \mathrm{p}<0.05,{ }^{*} \mathrm{p}$-value approaches significance $(\mathrm{p}<0.1)$.

significantly altered when normalized CBF was used (Supplementary Fig. 3c,d). Investigation of age-related changes in the cortical thickness of mice could provide more accurate CBF assessments with our technique.

In accordance with the $\mathrm{CBF}$ data, we also saw a parabolic trend in capillary density. This is in line with the strong correlation between the capillary density and the regional CBF found in rats ${ }^{72}$. Previous studies report decreased, unchanged or increased cerebral capillary density with age ${ }^{60,73}$. Although differences in the techniques, species, brain regions and age range of subjects may explain some of these discrepancies, capillary changes with aging have also been suggested to be biphasic ${ }^{73}$. Indeed, several studies report that capillary density increases until middle-age and then declines during later senescence both in rats ${ }^{74-76}$ and human ${ }^{77-79}$. This indicates a possible capillary response to altered cardiac output or blood pressure, or to meet the metabolic demands. The observed 
capillary density increase until middle-age in our study could be a regulatory response to decreased vascular oxygen content to maintain the tissue $\mathrm{pO}_{2}$ level. However, after middle-age we observed capillary loss possibly due to reduced angiogenesis capabilities. This hypothesis is in agreement with the observations in C57BL/6 J mice showing attenuated angiogenic and neurogenic response to vascular endothelial growth factor (VEGF) stimulation at 24 months of age compared with 3 and 12 months $^{80}$, suggesting maintained capacity for cerebral angiogenesis until middle-age, but a decline thereafter.

Overall, our study reveals an age-related decrease in resting cerebral tissue $\mathrm{pO}_{2}$ in conscious mice which was manifested mainly after middle-age. The findings suggest regulated capillary oxygen supply until middle-age to maintain the oxygen availability in the brain tissue. With further aging, tissue $\mathrm{pO}_{2}$ decreased significantly, hypothesized to be due to a capillary network failing to compensate larger decreases in arterial $\mathrm{pO}_{2}$. The observed substantial decrease in brain tissue $\mathrm{pO}_{2}$ and the presence of hypoxic micro-pockets after the middle-age are of significance because they could be involved in neurodegenerative diseases and cognition decline in elderly people.

\section{Methods}

Although this study was not blinded, the analysis of microscopic data was automated and the same parameters and algorithms were used to analyze all images limiting investigator bias. In addition, no data was discarded and care was taken to treat all groups equally during surgery, handling, training and imaging.

Synthesis of the PtP-C343 probe. The $\mathrm{O}_{2}$ - sensitive molecule PtP-C343 was synthetized following the general procedures reported in Finikova et al. ${ }^{25}$ and Vinogradov et al. ${ }^{81}$. Polyethylene glycol (PEG) units with the MW of $\sim 2000 \mathrm{Da}$ were used for the PEGylation of the dendrimer periphery. All compounds were characterized using routine techniques, including NMR, mass spectroscopy, GPC, and UV-Vis spectroscopy. The dye was then calibrated at $37^{\circ} \mathrm{C}$ and $7.2 \mathrm{pH}$ as described before ${ }^{82}$.

Animals. Animal handling and surgical procedures were approved by the ethics committee of the research center of the Montreal Heart Institute. All experiments were performed in accordance with the Canadian Council on Animal Care recommendations. Young adult (6-9 month-old), middle-aged (13-16 month-old) and old (24-28 month-old) C57BL/6 J healthy male mice were obtained from the colony of aged mice of the Quebec Network for Aging Research (RQRV) and housed in 12-hr light-dark cycle until imaging. Two batches of mice were used. The mice in batch 1 ( 7 young (average age $=8.8 \pm 0.1$ month-old), 6 middle-aged (average age $=15.3 \pm 0.1$ month-old), 7 old (average age $=27.0 \pm 0.1$ month-old)) were used to record tissue $\mathrm{pO}_{2}$. In batch 2 ( 8 young (average age $=6.9 \pm 0.2$ month-old), 8 middle-aged (average age $=14.1 \pm 0.1$ month-old), 8 old (average age $=24.9 \pm 0.1$ month-old)), vascular $\mathrm{pO}_{2}$ and capillary blood flow were measured. OCT and tail pulse oximetry were performed on both batches. 8-10 days before measurements, a thinned skull window was created over the left barrel cortex under $2.0 \%$ isoflurane anesthesia, as described in Shih et al. ${ }^{26}$. Briefly, the scalp was removed and a titanium-made head-plate was fixed on the skull using dental cement. The skull was then slowly thinned to translucency with a micro-drill (OmniDrill35, World Precision, USA). A $150 \mu$ m-thick cover glass was glued to the window using cyanoacrylate glue and the edges were sealed with dental cement to form a $3 \mathrm{~mm}$ diameter cranial window. For tissue $\mathrm{pO}_{2}$ measurements, a small thinned region at the edge of the cover glass $(\sim 0.5 \mathrm{~mm})$ was left uncovered with dental cement to allow later injection of the PtP-C343 dye into tissue through the soft thinned membrane. During the surgery, animals were fixed on a controlled physiological monitoring system (LabeoTech, Canada) which enabled continuous monitoring of the rectal temperature, respiration and heart rate. Ketoprofen ( $5 \mathrm{mg} / \mathrm{Kg}$, Merial, Canada) and buprenorphine $(0.05 \mathrm{mg} / \mathrm{Kg}$, Reckitt Benckiser Healthcare, UK) were injected before the surgery and baytril ( $5 \mathrm{mg} / \mathrm{Kg}$, Bayer, Germany) was injected after the surgery. Injections were repeated 24 hours after the surgery.

Awake imaging. During all measurements, animals were fixed on an angled treadmill wheel which allowed free movement of the limbs while the head was restrained by a titanium bar (Supplementary Fig. 1b). To minimize stress during the imaging sessions, animals were trained on the wheel over four fixation training sessions (starting after 3 days recovery following the surgery) to habituate to the head restraint. The length of time the mice were restrained was gradually increased from 10 to $45 \mathrm{~min}$ over 4 sessions.

Two-photon system. Two-photon imaging was performed using a custom-built laser-scanning microscope (Supplementary Fig. 1a) that used a consecutive sequence of $820 \mathrm{~nm}, 80 \mathrm{MHz}, 150 \mathrm{fs}$ pulses from MaiTai-BB laser oscillator (Newport corporation, USA) through an electro-optic modulator (ConOptics, USA) to adjust the gain and allow the generation of alternating "on" and "off" laser pulse periods for microsecond lifetime imaging. The optical beam was scanned in the $\mathrm{x}$-y plane by galvanometric mirrors (Thorlabs, USA). Reflected light was collected by a $20 \mathrm{X}$ objective (Olympus XLUMPLFLN-W, NA =1). Phosphorescent and fluorescent photons were separated by dichroic mirrors and relayed to two separate photomultiplier tubes (PMTs) for detection of PtP-C343 and dextran-FITC probes. Phosphorescent light was passed through a filter centered at $680 \mathrm{~nm}$ and detected by a first PMT (H7422, Hamamatsu Photonics, Japan). Fluorescent light was passed through a filter centered at $520 \mathrm{~nm}$ and forwarded to the second PMT (R3896, Hamamatsu Photonics, Japan).

Capillary blood flow imaging with two-photon fluorescence microscopy. $\quad \sim 200 \mu \mathrm{L} 2 \mathrm{MDa}$ dextran-FITC ( $50 \mathrm{mg} / \mathrm{ml}$ in saline, Sigma) was injected through the tail vein. Due to the injected fluorescent dye, the plasma appeared bright in the images while RBCs appeared as dark shadows. Capillary flow parameters were obtained from longitudinal and perpendicular line-scans over capillaries using the contrast in the images (see below and Fig. 4). Each line-scan measured 100 points along a straight line ( 20 $\mu \mathrm{m}$ long) at a line-rate of $800 \mathrm{~Hz}$. The line-scans were performed continuously and $250 \mathrm{~ms}$ segments of the line-scan data (200 lines) were used to create space-time images with dark streaks due to the motion of RBCs (Fig. 4a,b). The space-time images were 
used to obtain the following parameters for each capillary: (1) diameter by fitting the perpendicular scans with a Gaussian function whose full width at half maximum (FWHM) yielded an estimate of the internal diameter (Fig. 4a); (2) RBC velocity from the angle of the streaks in longitudinal space-time images (Fig. 4b) as described before $^{44}$; (3) capillary volumetric flow (RBC velocity $\times$ capillary cross-sectional area); (4) RBC flux (cells/s), determined as the number of dark shadows in the space-time images divided by the acquisition time of the images (the flux was obtained using both longitudinal and perpendicular scans and the average value was used); (5) hematocrit, calculated using the obtained values for RBC flux and volumetric flow ${ }^{44}$ (hematocrit $=\mathrm{RBC}$ flux $\times \mathrm{RBC}$ volume/capillary volumetric flow; RBC volume was considered to be $55 \mu \mathrm{m}^{3}$ for $\mathrm{C} 57 \mathrm{Bl} / 6$ mice ${ }^{83}$ ); and (6) capillary resistance, estimated from diameter and hematocrit using the equations given in literature ${ }^{84,85}$. All measured capillaries in each age group were pooled for age comparisons. For each animal, $1-3$ angiograms $(600 \mu \mathrm{m} \times 600 \mu \mathrm{m}$, $2 \mu \mathrm{m}$ steps) were also recorded for capillary density calculations.

Microvasculature segmentation and capillary density calculation. Microvasculature data from two-photon angiograms was segmented using a data-driven approach based on deep learning. Our deep learning model was based on the FC-DenseNet architecture proposed in Jégou et al. ${ }^{86}$. The model was composed of 97 convolutional layers with an input size of $256 \times 256 \times 1$. It had 11 dense blocks with 4, 5, 7, 9, 11, 13, 11, 9, 7, 5 and 4 convolutional layers in each block, respectively, with a growth rate of 24 . Each block in the first 5 dense blocks was followed by $2 \times 2$ pooling layers, whereas each block in the last 5 dense blocks was preceded by a $3 \times 3$ transposed convolution with stride 2 to compensate for the pooling operations. To train our segmentation model, we manually prepared ground truth labels of 8 angiograms captured with our two-photon microscopy. We augmented our dataset by rotation and flipping operations. The training of the model was performed on two NVIDIA TITAN X GPUs using the Theano library in Python. The training was performed by RMSprop optimizer with initial learning rate of $1 \mathrm{e}-4$ and an exponential decay of 0.995 after each epoch. To monitor the training process, we randomly selected $25 \%$ of our annotated data as a validation set. We used the validation set to stop the training process based on the mean Intersection over Union (IoU) metric with a patience of 25 epochs. The model was regularized with a weight decay of $1 \mathrm{e}-5$ and a dropout rate of 0.2 . We processed the output of the neural network by $3 \mathrm{D}$ morphological erosion and dilation operations to refine the segmentations. The vascular density was measured for each slice of the binarized (segmented) two-photon angiograms before and after applying a median filter (Fig. 4k). The application of the median filter removed the fine structures (capillaries). Then, the difference of these two densities (total vascular density and density of large vessels) provided an estimate of the capillary density.

Tissue $\mathrm{pO}_{2}$ imaging with two-photon phosphorescence lifetime microscopy. For tissue $\mathrm{pO}_{2}$ imaging, the PtP-C343 dye solution $(\sim 150 \mu \mathrm{M}$ in ACSF) was slowly injected into the brain tissue $\sim 300 \mu \mathrm{m}$ below the surface with a glass micropipette using a microsyringe injector (UMP3, World Precision, USA). $\sim 200 \mu \mathrm{l} 2 \mathrm{MDa}$ FITC-Dextran $(50 \mathrm{mg} / \mathrm{ml}$ in saline, Sigma) was also injected through the tail vein to visualize the vasculature. For each animal, grid measurements (225-400 points) were performed over 3-4 400 $\mu \mathrm{m} \times 400 \mu \mathrm{m}$ adjacent planes at different depths (30-40 $\mu \mathrm{m}$ intervals, up to 250-300 $\mu \mathrm{m}$ deep) (Fig. 2a and Supplementary Fig. 1e). Before each grid measurement, a fluorescent image was recorded to locate the sampling points in the tissue and find their distance to nearby arterioles or venules. At each point, 3000 excitation cycles were averaged before moving to the next point. Each excitation cycle consisted of $25 \mu$ s excitation period in which the laser pulse was "on" followed by $275 \mu$ s "off" period in which the phosphorescence emission was allowed to decay. Averaged phosphorescence decay at each point was fitted with a single-exponential curve to determine the phosphorescence lifetime. The lifetimes were then converted to $\mathrm{pO}_{2}$ using a calibration curve. For all imaging planes, large vessels (diameter $>10 \mu \mathrm{m}$ ) were graphed and labeled as arterioles or venules. The distance of each $\mathrm{pO}_{2}$ sampling point to closest arteriole and venule (in 3D) was then found. All sampling points in each age group were pooled to find the average tissue $\mathrm{pO}_{2}$, spatial heterogeneity of tissue oxygenation (defined as $\mathrm{SD} / \mathrm{mean}$ ) and the fraction of sampled points with hypoxic $\mathrm{pO}_{2}$ (here defined as $\mathrm{pO}_{2}<5 \mathrm{mmHg}$ ). In addition, $\mathrm{pO}_{2}$ profiles from arterioles and venules were obtained by plotting the points versus their distance from closest arteriole or venule. For venular profiles, the points within $100 \mu \mathrm{m}$ from an arteriole were excluded to avoid the contamination of venular profiles with the dominant effect of arterioles. For a regional study of tissue oxygenation, sampled points were divided into three categories: (1) "near arterioles", including the points within $100 \mu \mathrm{m}$ from an arteriole; (2) "near venules", including the points within $100 \mu \mathrm{m}$ from a venule, but at least $100 \mu \mathrm{m}$ from the closest arteriole, and (3) "capillary bed" including the points which were at least $100 \mu \mathrm{m}$ distant from the closest arteriole or venule. Average tissue $\mathrm{pO}_{2}$ was then obtained for each region.

Estimation of net oxygen consumption rate in cerebral tissue. For simplicity, we assumed a uniform capillary $\mathrm{O}_{2}$ supply in tissue, and a modification of the Krogh model ${ }^{50}$ was used to estimate the net oxygen consumption rate in the tissue (OC), defined as $\mathrm{CMRO}_{2}$ minus capillary $\mathrm{O}_{2}$ supply per unit volume of the tissue (Fig. 6b):

$$
p \mathrm{O}_{2}(r)=p \mathrm{O}_{2 \text { art }}+\frac{O C}{4 \alpha D}\left[\left(r^{2}-R_{\text {art }}^{2}\right)-2 R_{t}^{2} \ln \left(r / R_{\text {art }}\right)\right]
$$

$\mathrm{pO}_{2}$ art is the arterial $\mathrm{pO}_{2}, \mathrm{R}_{\mathrm{art}}$ is the mean arterial radius, $\mathrm{R}_{\mathrm{t}}$ is the radius of the Krogh cylinder, $\alpha$ is oxygen solubility $\left(1.27 \times 10^{-3} \mu \mathrm{moleO}_{2} / \mathrm{ml} / \mathrm{mmHg}\right)^{51}$, and $D$ is oxygen diffusivity in tissue $\left(\sim 4000 \mu \mathrm{m}^{2} / \mathrm{s}\right)^{51}$. Tissue $\mathrm{pO}_{2}$ profiles around arterioles, obtained from tissue $\mathrm{pO}_{2}$ maps, were fitted with the Krogh model to find $\mathrm{OC}$ and $\mathrm{pO}_{2 \text {,art }} \cdot \mathrm{R}_{\mathrm{t}}$ was determined as the distance at which the curve reached a plateau. 
Vascular $\mathrm{pO}_{2}$ imaging with two-photon phosphorescence lifetime microscopy. The PtP-C343 dye solution $(\sim 50 \mathrm{mg} / \mathrm{ml}$ in saline, $\sim 200 \mu \mathrm{ll})$ was injected through the tail vein. The fluorescent signal of the dye allowed visualization of the vasculature without the need for FITC-Dextran injection. In each mouse, a few penetrating arterioles and venules were chosen and vascular $\mathrm{pO}_{2}$ was measured at $30-40 \mu \mathrm{m}$ depth intervals, starting right after they branched from pial vessels up to the depth of $\sim 200 \mu \mathrm{m}$ (Fig. 1a). Each vascular $\mathrm{pO}_{2}$ measurement consisted of a line grid measurement with 10-15 points which yielded a parabolic $\mathrm{pO}_{2}$ profile whose maximum was used as $\mathrm{pO}_{2}$ at the center of the vessel. $\mathrm{pO}_{2}$ measurement principles were similar to tissue $\mathrm{pO}_{2}$ imaging described above. Obtained $\mathrm{pO}_{2}$ values were converted to oxygen saturation of hemoglobin $\left(\mathrm{SO}_{2}\right)$ using the Hill's equation (for C57BL/6 mice: $\mathrm{n}=2.59$ and $\mathrm{P} 50=40.2)^{87}$. For each vessel, average $\mathrm{pO}_{2}$ and $\mathrm{SO}_{2}$ over the first $150 \mu \mathrm{m}$ of depth were obtained. Average $\mathrm{pO}_{2}$ and $\mathrm{SO}_{2}$ values were then pooled in each group for age comparisons. Oxygen extraction fraction $\left(\mathrm{OEF}=\left(\mathrm{S}_{\mathrm{a}} \mathrm{O}_{2}-\mathrm{S}_{\mathrm{v}} \mathrm{O}_{2}\right) / \mathrm{S}_{\mathrm{a}} \mathrm{O}_{2}\right)$ was also obtained from average arteriolar and venular $\mathrm{SO}_{2}$ values.

OCT setup. Supplementary Fig. If shows a simplified layout of the OCT setup. Light originating from a superluminescent diode (SLD) source (LS2000C, Thorlabs) had a bandwidth of $200 \mathrm{~nm}$, yielding an axial resolution of $\sim 3.5 \mu \mathrm{m}$. Light was first sent to a circulator and divided by a 5/95 fiber splitter into reference and sample arms. Scanning on the sample was performed using a dual galvanometer system (Thorlabs) to be imaged using a $5 \mathrm{X}$ infinity corrected objective (Edmund Optics, USA) yielding a lateral resolution of $8.5 \mu \mathrm{m}$. In each arm, polarization control was integrated to maximize contrast. A custom-built spectrometer based on a volume holographic grating (HD1145, Wasatch Photonics, USA) was used as the detector with a high-speed 2048 pixel line camera (2048 R, Sensors Unlimited, USA) coupled to a $50 \mathrm{~mm}$ SWIR lens (Edmund Optics, USA).

Non-capillary blood flow measurements with Doppler-OCT. For each mouse, an OCT angiogram and a 3D Doppler OCT volume were acquired over a cortical surface of $\sim 700 \mu \mathrm{m} \times 700 \mu \mathrm{m}$. First, an angiogram volume $(512 \times 512$ pixels) was acquired (Fig. $3 \mathrm{a})$. In each volume, B-scans were repeated twice before moving to the next line. A total of 10 volumes were acquired for averaging purposes at a line rate of $40 \mathrm{~Hz}$. Then, a Doppler OCT scan was performed by oversampling in the $\mathrm{x}$-direction $(\mathrm{nx}=2048, \mathrm{ny}=512)$ to enable the computation of the phase between adjacent overlapping A-lines. The line rate was set to $24 \mathrm{~Hz}$. The Doppler volume was repeated 10 times for averaging. Doppler OCT image reconstruction was done in Matlab. Spectral shaping of the interference signal using a Hanning window was used to eliminate side lobes in the final image at the expense of broadening axial resolution to $\sim 3.8 \mu \mathrm{m}$. Automatic dispersion compensation to the second and third order dispersion imbalance was implemented per the procedure described in Wojtkowski et al. ${ }^{88}$. Optimization was done on the first frame of each acquisition to obtain the dispersion coefficients which were then applied to the rest of the acquisition. Reconstruction of flow speed was based on a moving-scatterer-sensitive reconstruction technique ${ }^{34,89,90}$ which uses the Kasai Autocorrelator ${ }^{91}$. A digital high pass filter was used to remove the stationary scattering components from the OCT image. For angiography image reconstruction, spectral shaping and dispersion compensation was identical to above. Frame differences were then computed in pairs (for repeated frames) and their variance were averaged over the 10 volumes repetition.

Obtained 3D Doppler OCT datasets consisted of en face slices of z-projection blood velocity maps at cortical depth intervals of $\sim 3.8 \mu \mathrm{m}$. Pial vessels generated both positive and negative Doppler shifts because of their undulating shape, but penetrating arterioles and venules exhibited pure positive or negative Doppler shifts (Fig. 3b). Therefore, in our analyses we excluded the top $50 \mu \mathrm{m}$ of the OCT datasets. For each slice in the OCT velocity volume, arterioles and venules were detected by a threshold filter (Fig. 3d) and their minor and major axis lengths, projected area and average projected velocity were measured. Diameter was estimated by minor axis length, flow was calculated as the product of projected area and projected velocity and projected velocity was converted to actual velocity along the vessel path using the ratio of the major and minor axis lengths. Total flow in the imaged region was obtained by summation of the flow in individual vessels over the en face plane. This yielded total flow in $\mathrm{ml} / \mu^{2} / \mathrm{min}$, which was converted to $\mathrm{ml} / \mathrm{g} / \mathrm{min}$ by normalizing to the cortical mass corresponding to the scanned area assuming a cortical thickness of $1.5 \mathrm{~mm}$ for the barrel field of C57/BL6 mice $\mathrm{e}^{92}$ and brain density of $1.05 \mathrm{~g} / \mathrm{m}^{93}$. All parameters were averaged over the depth of 50-650 $\mu \mathrm{m}$ (Fig. 3e).

It has been established that flow in penetrating arterioles and venules can be assigned to well-defined cortical regions ${ }^{94}$. Thus, total blood flow over the scanning area averaged over the depth of 50-100 $\mu \mathrm{m}$ in which penetrating arterioles and venules have just branched from pial vessels, but before further branching to smaller vessels not

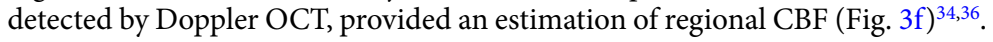

Identification of arterioles, venules and capillaries. The camera images taken during the surgery were used to identify pial arterioles and venules based on their morphology; pial arteries tend to be thinner, straighter, and gradually branching into smaller vessels, while pial veins are thicker, more curvy, and branching into vessels of all calibers ${ }^{95}$. Penetrating arterioles and venules were identified by tracking the pial vessels until they dive. This initial vessel identification was then further confirmed by $\mathrm{pO}_{2}$ measurements and OCT data (downward flow in arterioles and upward flow in venules). Capillaries were defined as microvessels a few branches away from penetrating vessels with diameter less than $10 \mu \mathrm{m}$.

Estimation of $\mathrm{CMRO}_{2}$. For the mice in which we had both vascular $\mathrm{pO}_{2}$ and $\mathrm{CBF}$ measures over the same cortical region, we estimated the $\mathrm{CMRO}_{2}$ from $\mathrm{CMRO}_{2}=\mathrm{CBF}\left(\left[\mathrm{O}_{2}\right]_{\mathrm{a}}-\left[\mathrm{O}_{2}\right]_{\mathrm{v}}\right)$ (Fig. 6a). CBF was obtained from OCT data as total blood flow averaged through the depth of 50-100 $\mu \mathrm{m}$. Vascular $\mathrm{pO}_{2}$ data from two-photon measurements was used to calculate the average arterial and venular $\mathrm{O}_{2}$ contents $\left(\left[\mathrm{O}_{2}\right]_{\mathrm{a}}\right.$ and $\left.\left[\mathrm{O}_{2}\right]_{\mathrm{v}}\right)$ over the same depth using the equation $\left[\mathrm{O}_{2}\right]=\alpha \cdot \mathrm{pO}_{2}+4 \mathrm{Hct} \cdot \mathrm{C}_{\mathrm{Hb}} \cdot \mathrm{SO}_{2}{ }^{95} \cdot C_{\mathrm{Hb}}$ is hemoglobin content of $\mathrm{RBC}(5.3 \mu$ mole $\mathrm{Hb} / \mathrm{ml}$ $\mathrm{RBC})^{95}$ and $\mathrm{Hct}$ is hematocrit, assumed to be equal to the systemic hematocrit. 
$\mathrm{O}_{2}$ delivery by individual arterioles. In the mice with both vascular $\mathrm{pO}_{2}$ and Doppler OCT measures over the same region, we were able to detect arterioles for which we had both vascular $\mathrm{pO}_{2}$ versus depth and mean blood flow (Fig. 7a). A simple mass balance equation yielded $\mathrm{O}_{2}$ delivery from these arterioles to surrounding tissue (Fig. 7b):

$$
\dot{O}_{2}=-Q \frac{d\left[\mathrm{O}_{2}\right]}{d z}
$$

$\dot{\mathrm{O}}_{2}$ is $\mathrm{O}_{2}$ delivery to surrounding tissue per unit length of the vessel $[\mu \mathrm{mol} / \mathrm{min} / \mu \mathrm{m}], Q$ is $\operatorname{mean}$ blood flow in the arteriole, $\left[\mathrm{O}_{2}\right]$ is oxygen content of the blood, and $z$ is depth. Average $\mathrm{dSO}_{2} / \mathrm{dz}$ was obtained for each vessel over the depth of $0-150 \mu \mathrm{m}$ and was converted to $\mathrm{d}\left[\mathrm{O}_{2}\right] / \mathrm{dz}$. Average flow in the vessel was also obtained over the same depth range.

Systemic hematocrit. Systemic hematocrit was measured on a separate batch of age-matched mice (10 young, 9 middle-aged, and 8 old mice). Two hours after the beginning of the light cycle, blood was harvested from the saphenous vein of non-fasted mice and put in microhematocrit tubes by capillary action. Tubes were then sealed and spun in a microhematocrit centrifuge at high speed for 5 minutes. The length taken up by centrifuged red cells was measured and divided by the whole microhematocrit tube length to determine the hematocrit percentage.

Statistical analysis. The results are presented as mean \pm s.e.m. Statistical significance was calculated using ANOVA followed by Tukey HSD post hoc test. Statistical significance was assigned at $* \mathrm{p}<0.05, * * \mathrm{p}<0.01$, $* * * \mathrm{p}<0.001, * * * * \mathrm{p}<0.0001$ and $* * * * * \mathrm{p}<0.00001$. The sample sizes were chosen empirically based on our previous experience.

Code availability. Custom-written code in Matlab or Python are available from the corresponding author upon reasonable request.

Data availability. The authors declare that the main part of data supporting the findings of this study is available within the paper and its supplementary figures. Data not presented within the paper or supplementary figures are available from the corresponding author upon reasonable request.

\section{References}

1. Hasher, L. \& Zacks, R. T. Working Memory, Comprehension, and Aging: A Review and a New View. in Psychology of Learning and Motivation (ed. Gordon H. Bower) Volume 22, 193-225 (Academic Press, 1988).

2. Salthouse, T. The processing-speed theory of adult age differences in cognition. Psychol. Rev. 103, 403-28 (1996).

3. Bertsch, K. et al. Resting cerebral blood flow, attention, and aging. Brain Res. 1267, 77-88 (2009).

4. Eustache, F. et al. Healthy aging, memory subsystems and regional cerebral oxygen consumption. Neuropsychologia 33, 867-887 (1995).

5. Kalaria, R. N. Cerebral vessels in ageing and Alzheimer's disease. Pharmacol. Ther. 72, 193-214 (1996).

6. Hofman, A. et al. Atherosclerosis, apolipoprotein E, and prevalence of dementia and Alzheimer's disease in the Rotterdam Study. The Lancet 349, 151-154 (1997)

7. Dickstein, D. L. et al. Role of Vascular Risk Factors and Vascular Dysfunction in Alzheimer's Disease. Mt. Sinai J. Med. J. Transl. Pers. Med. 77, 82-102 (2010).

8. Yaffe, K. et al. Early Adult to Midlife Cardiovascular Risk Factors and Cognitive Function. Circulation 129, 1560-1567 (2014).

9. Berman, R. F., Goldman, H. \& Altman, H. J. Age-related changes in regional cerebral blood flow and behavior in Sprague-Dawley rats. Neurobiol. Aging 9, 691-696 (1988).

10. Peers, C. et al. Hypoxia and Neurodegeneration. Ann. N. Y. Acad. Sci. 1177, 169-177 (2009).

11. Peers, C., Pearson, H. A. \& Boyle, J. P. Hypoxia and Alzheimer's disease. Essays Biochem. 43, 153 (2007).

12. Hota, K. B., Hota, S. K. \& Singh, S. B. Neurodegeneration in Hypoxia: Implications in Aging. in Brain Aging and Therapeutic Interventions (eds Thakur, M. K. \& Rattan, S. I. S.) 177-189 (Springer Netherlands, 2012).

13. Hornbein, T. F. Long Term Effects of High Altitude on Brain Function. Int J Sports Med 13, S43-S45 (2008).

14. Nelson, T. O. et al. Cognition and metacognition at extreme altitudes on Mount Everest. J. Exp. Psychol. Gen. 119, 367-374 (1990).

15. Regard, M., Oelz, O., Brugger, P. \& Landis, T. Persistent cognitive impairment in climbers after repeated exposure to extreme altitude. Neurology 39, 210-210 (1989).

16. Titus, A. D. J. et al. Hypobaric hypoxia-induced dendritic atrophy of hippocampal neurons is associated with cognitive impairment in adult rats. Neuroscience 145, 265-278 (2007).

17. Rapino, C. et al. HIF-1 $\alpha$ cytoplasmic accumulation is associated with cell death in old rat cerebral cortex exposed to intermittent hypoxia. Aging Cell 4, 177-185 (2005).

18. Gatto, R., Hoffman, W. E., Mueller, M., Paisansathan, C. \& Charbel, F. Age effects on brain oxygenation during hypercapnia. J. Biomed. Opt. 12, 062113 (2007).

19. Dubeau, S., Ferland, G., Gaudreau, P., Beaumont, E. \& Lesage, F. Cerebrovascular hemodynamic correlates of aging in the Lou/c rat: A model of healthy aging. NeuroImage 56, 1892-1901 (2011).

20. Herrmann, M. J., Walter, A., Ehlis, A.-C. \& Fallgatter, A. J. Cerebral oxygenation changes in the prefrontal cortex: Effects of age and gender. Neurobiol. Aging 27, 888-894 (2006).

21. Hock, C. et al. Age Dependency of Changes in Cerebral Hemoglobin Oxygenation during Brain Activation: A Near-Infrared Spectroscopy Study. J. Cereb. Blood Flow Metab. 15, 1103-1108 (1995).

22. Mehagnoul-Schipper, D. J. et al. Simultaneous measurements of cerebral oxygenation changes during brain activation by nearinfrared spectroscopy and functional magnetic resonance imaging in healthy young and elderly subjects. Hum. Brain Mapp. 16, 14-23 (2002).

23. Schroeter, M. L., Zysset, S., Kruggel, F. \& von Cramon, D. Y. Age dependency of the hemodynamic response as measured by functional near-infrared spectroscopy. NeuroImage 19, 555-564 (2003).

24. Sakadzic, S. et al. Two-photon high-resolution measurement of partial pressure of oxygen in cerebral vasculature and tissue. Nat Meth 7, 755-759 (2010).

25. Finikova, O. S. et al. Oxygen Microscopy by Two-Photon-Excited Phosphorescence. ChemPhysChem 9, 1673-1679 (2008). 
26. Shih, A. Y., Mateo, C., Drew, P. J., Tsai, P. S. \& Kleinfeld, D. A Polished and Reinforced Thinned-skull Window for Long-term Imaging of the Mouse Brain. J. Vis. Exp. JoVE 3742, https://doi.org/10.3791/3742 (2012).

27. Peng, S.-L. et al. Age-related increase of resting metabolic rate in the human brain. NeuroImage 98, 176-183 (2014).

28. Aanerud, J. et al. Brain Energy Metabolism and Blood Flow Differences in Healthy Aging. J. Cereb. Blood Flow Metab. 32, 1177-1187 (2012).

29. Lu, H. et al. Alterations in Cerebral Metabolic Rate and Blood Supply across the Adult Lifespan. Cereb. Cortex 21, 1426-1434 (2011).

30. Cardus, J. et al. Increase in Pulmonary Ventilation-Perfusion Inequality with Age in Healthy Individuals. Am. J. Respir. Crit. Care Med. 156, 648-653 (1997).

31. Klæstrup, E. et al. Reference intervals and age and gender dependency for arterial blood gases and electrolytes in adults. Clin. Chem. Lab. Med. 49, 1495-1500 (2011).

32. Korkushko, O. V., Ivanov, L. A., Pisaruk, A. V. \& Chebotarev, N. D. The respiratory function of blood in elderly and old age and the factors that determine it. Hum. Physiol. 35, 163-169 (2009).

33. Kasischke, K. A. et al. Two-Photon NADH Imaging Exposes Boundaries of Oxygen Diffusion in Cortical Vascular Supply Regions. J. Cereb. Blood Flow Metab. 31, 68-81 (2011).

34. Srinivasan, V. J. et al. Quantitative cerebral blood flow with Optical Coherence Tomography. Opt. Express 18, 2477-2494 (2010).

35. Chong, S. P., Merkle, C. W., Leahy, C. \& Srinivasan, V. J. Cerebral metabolic rate of oxygen (CMRO(2)) assessed by combined Doppler and spectroscopic OCT. Biomed. Opt. Express 6, 3941-3951 (2015).

36. Srinivasan, V. J. et al. Multiparametric, Longitudinal Optical Coherence Tomography Imaging Reveals Acute Injury and Chronic Recovery in Experimental Ischemic Stroke. PLOS ONE 8, e71478 (2013).

37. Nakao, Y. et al. Effects of anesthesia on functional activation of cerebral blood flow and metabolism. Proc. Natl. Acad. Sci. 98, 7593-7598 (2001).

38. Barsha, G., Denton, K. M. \& Mirabito Colafella, K. M. Sex- and age-related differences in arterial pressure and albuminuria in mice. Biol. Sex Differ. 7, 57 (2016).

39. Kurtz, T. W., Lujan, H. L. \& DiCarlo, S. E. The $24 \mathrm{~h}$ pattern of arterial pressure in mice is determined mainly by heart rate-driven variation in cardiac output. Physiol. Rep. 2, e12223 (2014).

40. Talan, M. I. \& Engel, B. T. Effect of sympathetic blockade on diurnal variation of hemodynamic patterns. Am. J. Physiol. - Regul. Integr. Comp. Physiol. 256, R778 (1989).

41. Veerman, D. P., Imholz, B. P. M., Wieling, W., Wesseling, K. H. \& van Montfrans, G. A. Circadian Profile of Systemic Hemodynamics. Hypertension 26, 55 (1995).

42. Delp, M. D., Evans, M. V. \& Duan, C. Effects of aging on cardiac output, regional blood flow, and body composition in Fischer-344 rats. J. Appl. Physiol. 85, 1813 (1998).

43. Moeini, M. et al. Effects of anesthesia on the cerebral capillary blood flow in young and old mice. in9329, 932929-9329-6 (2015).

44. Desjardins, M., Berti, R., Lefebvre, J., Dubeau, S. \& Lesage, F. Aging-related differences in cerebral capillary blood flow in anesthetized rats. Neurobiol. Aging 35, 1947-1955 (2014).

45. Angleys, H., Østergaard, L. \& Jespersen, S. N. The effects of capillary transit time heterogeneity (CTH) on brain oxygenation. J. Cereb. Blood Flow Metab. 35, 806-817 (2015).

46. Jespersen, S. N. \& Østergaard, L. The roles of cerebral blood flow, capillary transit time heterogeneity, and oxygen tension in brain oxygenation and metabolism. J. Cereb. Blood Flow Metab. 32, 264-277 (2012).

47. De Vis, J. B. et al. Age-related changes in brain hemodynamics; A calibrated MRI study. Hum. Brain Mapp. 36, 3973-3987 (2015).

48. Burns, A. \& Tyrrell, P. Association of Age with Regional Cerebral Oxygen Utilization: A Positron Emission Tomography Study. Age Ageing 21, 316-320 (1992).

49. Pantano, P. et al. Regional cerebral blood flow and oxygen consumption in human aging. Stroke 15, 635-641 (1984).

50. Krogh, A. The number and distribution of capillaries in muscles with calculations of the oxygen pressure head necessary for supplying the tissue. J. Physiol. 52, 409-415 (1919).

51. Sakadžić, S. et al. Two-photon microscopy measurement of cerebral metabolic rate of oxygen using periarteriolar oxygen concentration gradients. 3, 045005-3-8 (2016).

52. Intaglietta, M., Johnson, P. C. \& Winslow, R. M. Microvascular and tissue oxygen distribution. Cardiovasc. Res. 32, 632-643 (1996).

53. Sharan, M., Vovenko, E. P., Vadapalli, A., Popel, A. S. \& Pittman, R. N. Experimental and Theoretical Studies of Oxygen Gradients in Rat Pial Microvessels. J. Cereb. Blood Flow Metab. 28, 1597-1604 (2008).

54. Lyons, D. G., Parpaleix, A., Roche, M. \& Charpak, S. Mapping oxygen concentration in the awake mouse brain. eLife 5, e12024 (2016).

55. Edwards, M. J. \& Rigas, D. A. Electrolyte-Labile Increase of Oxygen Affinity during In Vivo Aging of Hemoglobin. J. Clin. Invest. 46, $1579-1588$ (1967)

56. Samaja, M. et al. Human red cell age, oxygen affinity and oxygen transport. Respir. Physiol. 79, 69-79 (1990).

57. Samaja, M., Rovida, E., Motterlini, R. \& Tarantola, M. The Relationship Between the Blood Oxygen Transport and the Human Red Cell Aging Process. in Red Blood Cell Aging (eds. Magnani, M. \& De Flora, A.) 115-123 (Springer US, 1991).

58. Smith, E. E., Schneider, J. A., Wardlaw, J. M. \& Greenberg, S. M. Cerebral Microinfarcts: The Invisible Lesions. Lancet Neurol. 11, 272-282 (2012)

59. Wang, M. et al. Cognitive deficits and delayed neuronal loss in a mouse model of multiple microinfarcts. J. Neurosci. Off. J. Soc. Neurosci. 32, 17948-17960 (2012).

60. Farkas, E. \& Luiten, P. G. Cerebral microvascular pathology in aging and Alzheimer's disease. Prog. Neurobiol. 64, 575-611 (2001).

61. Cidis Meltzer, C. et al. Does Cerebral Blood Flow Decline in Healthy Aging? A PET Study with Partial-Volume Correction. J. Nucl. Med. 41, 1842-1848 (2000)

62. Itoh, M. et al. Stability of Cerebral Blood Flow and Oxygen Metabolism during Normal Aging. Gerontology 36, 43-48 (1990).

63. Krejza, J. et al. Transcranial color Doppler sonography of basal cerebral arteries in 182 healthy subjects: age and sex variability and normal reference values for blood flow parameters. Am. J. Roentgenol. 172, 213-218 (1999).

64. Bentourkia, M. et al. Comparison of regional cerebral blood flow and glucose metabolism in the normal brain: effect of aging. J. Neurol. Sci. 181, 19-28 (2000).

65. Pagani, M. et al. Regional cerebral blood flow as assessed by principal component analysis and 99mTc-HMPAO SPET in healthy subjects at rest: normal distribution and effect of age and gender. Eur. J. Nucl. Med. Mol. Imaging 29, 67-75 (2002).

66. Chen, J. J., Rosas, H. D. \& Salat, D. H. Age-Associated Reductions in Cerebral Blood Flow Are Independent from Regional Atrophy. NeuroImage 55, 468-478 (2011).

67. Martin, A. J., Friston, K. J., Colebatch, J. G. \& Frackowiak, R. S. J. Decreases in Regional Cerebral Blood Flow with Normal Aging. J. Cereb. Blood Flow Metab. 11, 684-689 (1991).

68. Moustafa, H. F. \& Hopewell, J. W. Age related changes in cardiac output, cephalic and cerebral blood flow in the rat. Int. J. Appl. Radiat. Isot. 32, 309-312 (1981)

69. Viboolvorakul, S. \& Patumraj, S. Exercise Training Could Improve Age-Related Changes in Cerebral Blood Flow and Capillary Vascularity through the Upregulation of VEGF and eNOS. BioMed Res. Int. 2014, 230791 (2014).

70. Ohata, M., Sundaram, U., Fredericks, W. R., London, E. D. \& Rapoport, S. I. Regional cerebral blood flow during development and ageing of the rat brain. Brain 104, 319-332 (1981). 
71. Lartaud, I., Bray-des-Boscs, L., Chillon, J. M., Atkinson, J. \& Capdeville-Atkinson, C. In vivo cerebrovascular reactivity in Wistar and Fischer 344 rat strains during aging. Am. J. Physiol. - Heart Circ. Physiol. 264, H851 (1993).

72. Gjedde, A. \& Diemer, N. H. Double-Tracer Study of the Fine Regional Blood-Brain Glucose Transfer in the Rat by ComputerAssisted Autoradiography. J. Cereb. Blood Flow Metab. 5, 282-289 (1985).

73. Riddle, D. R., Sonntag, W. E. \& Lichtenwalner, R. J. Microvascular plasticity in aging. Ageing Res. Rev. 2, 149-168 (2003).

74. Hinds, J. W. \& McNelly, N. A. Capillaries in aging rat olfactory bulb: A quantitative light and electron microscopic analysis. Neurobiol. Aging 3, 197-207 (1982).

75. Wilkinson, J. H., Hopewell, J. W. \& Reinhold, H. S. A quantitative study of age-related changes in the vascular architecture of the rat cerebral cortex. Neuropathol. Appl. Neurobiol. 7, 451-462 (1981).

76. Villena, A., Vidal, L., Díaz, F. \& Pérez De Vargas, I. Stereological changes in the capillary network of the aging dorsal lateral geniculate nucleus. Anat. Rec. A. Discov. Mol. Cell. Evol. Biol. 274A, 857-861 (2003).

77. Bell, M. \& Ball, M. J. Morphometric comparison of hippocampal microvasculature in ageing and demented people: Diameters and densities. Acta Neuropathol. (Berl.) 53, 299-318 (1981)

78. Hunziker, O., Abdel'al, S. \& Schulz, U. The Aging Human Cerebral Cortex: A Stereological Characterization of Changes in the Capillary Net. J. Gerontol. 34, 345-350 (1979).

79. Meier-Ruge, W., Hunziker, O., Schulz, U., Tobler, H.-J. \& Schweizer, A. Stereological changes in the capillary network and nerve cells of the aging human brain. Mech. Ageing Dev. 14, 233-243 (1980).

80. Gao, P. et al. Attenuation of Brain Response to VEGF-mediated Angiogenesis and Neurogenesis in Aged Mice. Stroke J. Cereb. Circ. 40, 3596-3600 (2009).

81. Vinogradov, S. A. Arylamide Dendrimers with Flexible Linkers via Haloacyl Halide Method. Org. Lett. 7, 1761-1764 (2005).

82. Rozhkov, V., Wilson, D. \& Vinogradov, S. Phosphorescent Pd Porphyrin-Dendrimers: Tuning Core Accessibility by Varying the Hydrophobicity of the Dendritic Matrix. Macromolecules 35, 1991-1993 (2002).

83. Wirth-Dzięciolowska, E., Karaszewska, J., Pyśniak, K., Smolińska, M. \& Gajewska, M. Selected peripheral blood cell parameters in twelve inbred strains of laboratory mice. Anim. Sci. Pap. Rep. 27, 69-77 (2009).

84. Pries, A. R., Neuhaus, D. \& Gaehtgens, P. Blood viscosity in tube flow: dependence on diameter and hematocrit. Am. J. Physiol. Heart Circ. Physiol. 263, H1770 (1992).

85. Schmid, F., Reichold, J., Weber, B. \& Jenny, P. The impact of capillary dilation on the distribution of red blood cells in artificial networks. Am. J. Physiol. - Heart Circ. Physiol. 308, H733 (2015).

86. Jégou, S., Drozdzal, M., Vazquez, D., Romero, A. \& Bengio, Y. The One Hundred Layers Tiramisu: Fully Convolutional DenseNets for Semantic Segmentation. in 2017 IEEE Conference on Computer Vision and Pattern Recognition Workshops (CVPRW) 1175-1183, https://doi.org/10.1109/CVPRW.2017.156 (2017).

87. Uchida, K., Reilly, M. P. \& Asakura, T. Molecular Stability and Function of Mouse Hemoglobins. Zoolog. Sci. 15, 703-706 (1998).

88. Wojtkowski, M. et al. Ultrahigh-resolution, high-speed, Fourier domain optical coherence tomography and methods for dispersion compensation. Opt. Express 12, 2404-2422 (2004).

89. Ren, H., Sun, T., MacDonald, D. J., Cobb, M. J. \& Li, X. Real-time in vivo blood-flow imaging by moving-scatterer-sensitive spectraldomain optical Doppler tomography. Opt. Lett. 31, 927-929 (2006).

90. Baraghis, E. et al. Measurement of cerebral microvascular compliance in a model of atherosclerosis with optical coherence tomography. Biomed. Opt. Express 2, 3079-3093 (2011).

91. Kasai, C., Namekawa, K., Koyano, A. \& Omoto, R. Real-Time Two-Dimensional Blood Flow Imaging Using an Autocorrelation Technique. IEEE Trans. Sonics Ultrason. 32, 458-464 (1985).

92. Bittolo, T. et al. Pharmacological treatment with mirtazapine rescues cortical atrophy and respiratory deficits in MeCP2 null mice 6, 19796 (2016)

93. Kretschmann, H., Kammradt, G., Krauthausen, I., Sauer, B. \& Wingert, F. Brain growth in man. Bibl Anat 28, 1-26 (1986),

94. Nishimura, N., Schaffer, C. B., Friedman, B., Lyden, P. D. \& Kleinfeld, D. Penetrating arterioles are a bottleneck in the perfusion of neocortex. Proc. Natl. Acad. Sci. 104, 365-370 (2007).

95. Gagnon, L. et al. Quantifying the Microvascular Origin of BOLD-fMRI from First Principles with Two-Photon Microscopy and an Oxygen-Sensitive Nanoprobe. J. Neurosci. 35, 3663-3675 (2015).

\section{Acknowledgements}

The authors thank Marc-Antoine Gillis and Natacha Duquette (Montreal Heart Institute) for their help with animal preparations and Stéphanie Miard (IUCPQ) for the hematocrit count. The authors are also grateful to Sava Sakadzic (Harvard Medical School) for discussions on the $\mathrm{pO}_{2}$ results, Sergei Vinogradov (University of Pennsylvania) for useful comments on PtP-C343 probe synthesis and calibrating the probe for us, Tina Lam, Nadim Saade, Anjali Sharma, William Curtis, Yu-Chen Wang (McGill University), Emmanuel Roussakis (Harvard Medical School), and Tatiana Esipova (University of Pennsylvania) for assistance with PtP-C343 probe synthesis and characterization. We thank the RQRV (Réseau Québécois de Recherche sur le Vieillissement, in part funded by the Fonds de Recherche du Québec - Santé) for its valued contribution to the present study. This study was funded by a Canadian Institutes of Health Research (CIHR, 299166) operating grant and a Natural Sciences and Engineering Research Council of Canada (NSERC, 239876-2011) discovery grant to F. Lesage and a Natural Sciences and Engineering Research Council of Canada (NSERC, 06080-2017) grant to F. Picard. M. Moeini was supported by the MÉDITIS Program (École Polytechnique) and Fonds de Recherche du QuébecNature et Technologies (FRQNT).

\section{Author Contributions}

F.L. conceived and supervised the study. M.M. and F.L. designed the experiments and analyzed the data, with contributions from R.D., S.B. and D.B. M.M., X.L., P.A. and F.P. performed the experiments. M.M. synthetized the PtP-C343 dye under the supervision of A.K. D.B. helped in confirming the performance of the dye. F.P. provided the aged mice. M.M., F.L., D.B. and X.L. were involved in interpreting the findings. M.M. prepared the manuscript and figures. All authors edited and approved the manuscript.

\section{Additional Information}

Supplementary information accompanies this paper at https://doi.org/10.1038/s41598-018-26543-w.

Competing Interests: Dr. Lesage reports a minority ownership in LabeoTech Inc. 
Publisher's note: Springer Nature remains neutral with regard to jurisdictional claims in published maps and institutional affiliations.

(c) (i) Open Access This article is licensed under a Creative Commons Attribution 4.0 International License, which permits use, sharing, adaptation, distribution and reproduction in any medium or format, as long as you give appropriate credit to the original author(s) and the source, provide a link to the Creative Commons license, and indicate if changes were made. The images or other third party material in this article are included in the article's Creative Commons license, unless indicated otherwise in a credit line to the material. If material is not included in the article's Creative Commons license and your intended use is not permitted by statutory regulation or exceeds the permitted use, you will need to obtain permission directly from the copyright holder. To view a copy of this license, visit http://creativecommons.org/licenses/by/4.0/.

(C) The Author(s) 2018 